Florida International University FIU Digital Commons

6-26-2018

\title{
Spatial and Temporal Distribution of Total Phosphorus Concentration in Soil and Surface Water in the Everglades Protection Area
}

Shishir Kumar Sarker

Florida International University, ssark009@fiu.edu

DOI: $10.25148 /$ etd.FIDC006895

Follow this and additional works at: https://digitalcommons.fiu.edu/etd

Part of the Environmental Studies Commons

\section{Recommended Citation}

Sarker, Shishir Kumar, "Spatial and Temporal Distribution of Total Phosphorus Concentration in Soil and Surface Water in the Everglades Protection Area" (2018). FIU Electronic Theses and Dissertations. 3742.

https://digitalcommons.fiu.edu/etd/3742 


\section{FLORIDA INTERNATIONAL UNIVERSITY}

Miami, Florida

SPATIAL AND TEMPORAL DISTRIBUTION OF TOTAL PHOSPHORUS

CONCENTRATION IN SOIL AND SURFACE WATER IN THE EVERGLADES

PROTECTION AREA

A thesis submitted in partial fulfillment of the

requirements for the degree of

MASTER OF SCIENCE

in

ENVIRONMENTAL STUDIES

by

Shishir Kumar Sarker 
To: Dean Michael Heithaus

College of Arts, Sciences and Education

This thesis, written by Shishir Kumar Sarker, and entitled Spatial and Temporal

Distribution of Total Phosphorus Concentration in Soil and Surface Water in the Everglades Protection Area, having been approved in respect to style and intellectual content, is referred to you for judgment.

We have read this thesis and recommend that it be approved.

Leonard J. Scinto

Assefa M. Melesse

René M. Price, Major Professor

Date of Defense: June 26, 2018

The thesis of Shishir Kumar Sarker is approved.

Dean Michael Heithaus

College of Arts, Sciences and Education

Andrés G. Gil

Vice President for Research and Economic Development

and Dean of the University Graduate School

Florida International University, 2018 
(C) Copyright 2018 by Shishir Kumar Sarker

All rights reserved. 


\section{ACKNOWLEDGMENTS}

I am sincerely thankful to my major advisor, Dr. René Price, for providing me an opportunity to work in her lab. Her incessant guidance and support were essential in order to the completion of this project. Also, I am truly thankful to my committee member, Dr. Leonard Scinto for providing me REMAP soil data in order to complete this work. Also, his invaluable guidance helped me to overcome several challenges encountered throughout the time. I would like to extend my sincere gratitude to my committee member Dr. Assefa Melesse, for his suggestion and encouragement over the course of this project. I would also

like to thank Dr. Donnato Surrett, for providing me the ESM soil data which helped me to complete this project. I am also thankful to the Department of Earth and Environment for awarding me the assistantships that allowed me to complete my graduate degree. This thesis is based upon work supported by the National Science Foundation through the Florida Coastal Everglades Long-Term Ecological Research program under Grant. DEB123751. 


\title{
ABSTRACT OF THE THESIS \\ SPATIAL AND TEMPORAL DISTRIBUTION OF TOTAL PHOSPHORUS \\ CONCENTRATION IN SOIL AND SURFACE WATER IN THE EVERGLADES \\ PROTECTION AREA
}

by

\author{
Shishir Kumar Sarker \\ Florida International University, 2018 \\ Miami, Florida \\ Professor René M. Price, Major Professor
}

Draining of the Everglades allowed for the expansion of urban and agricultural development, reducing half of the size of the historic Everglades. The detrimental cascading effect on the Everglades ecosystem function is related to the total phosphorus (TP) concentrations of water inflow, the inflow rate and the distance from the discharge point. As Everglades restoration has approached 15 years since the inception of the Comprehensive Everglades Restoration Plan (CERP), there is a need to assess its progress across the ecosystem. Available data from 2004 to 2014 were collected for soils and from 2004 to 2016 for water to understand a decade of trends. Both Geographic Information System (GIS) and statistical data analysis were applied to determine changes in water quality and soil chemistry. Key findings indicate a declining trend in water TP, with mixed results for soil. Higher TP concentrations $(>10 \mu \mathrm{g} / \mathrm{L})$ were prevalent in areas less than 1 $\mathrm{km}$ from a canal or water discharge point for both soil and water. The TP in surface water was higher in the wet season compared to the dry season across the EPA possibly associated with hydrologic, climatic or other factors. 


\section{TABLE OF CONTENTS}

CHAPTER

PAGE

1. INTRODUCTION 1

2. METHODS..........................................................

2.1 Study Area....................................................... 8

2.2 Data Acquisition.................................................... 9

2.3 Database Compilation........................................... 10

2.4 Data Analysis.................................................... 12

2.4.1 Distance gradient analysis in surface water TP along EPA transect.12 2.4.2 Soil TP Distribution Analysis.............................14

2.4.3 Seasonality analysis of surface water TP $\ldots \ldots \ldots \ldots \ldots \ldots \ldots \ldots \ldots$

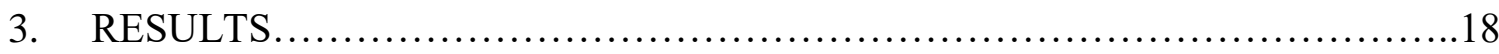

3.1 Distance gradient analysis in surface water TP along EPA Transect..........18

3.1.1 Water Conservation Area 1 Transect.............................18

3.1.2 Water Conservation Area 2 Transect............................19

3.1.3 Water Conservation Area 3 Transect............................19

3.1.4 Everglades National Park Transect...........................20

3.2 Soil TP distribution analysis......................................26

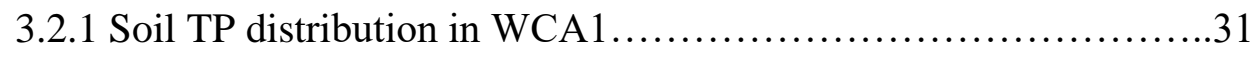

3.2.2 Soil TP distribution in WCA2 ................................. 32

3.2.3 Soil TP distribution in WCA3 ............................... 33

3.2.4 Soil TP distribution in ENP ................................ 34

3.3 Seasonality analysis of Surface Water TP............................. 36

3.3.1 Seasonal Trend of TP concentration in WCA1 ....................37

3.3.2 Seasonal Trend of TP concentration in WCA2 ....................38

3.3.3 Seasonal Trend of TP concentration in WCA3 ...................39

3.3.4 Seasonal Trend of TP concentration in ENP ..................40 


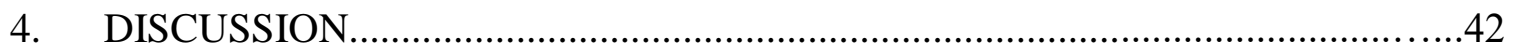

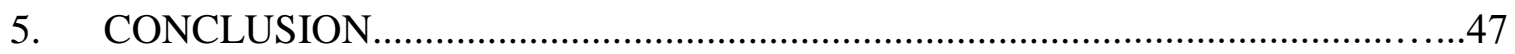

REFERENCES.............................................................. 48

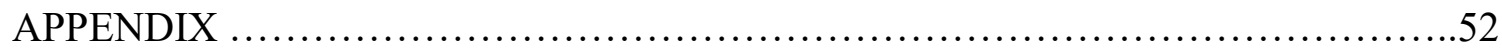




\section{LIST OF TABLES}

TABLE

PAGE

1. Number of monthly sample records collected for study sites across the entire EPA for surface water and soil based on multiple sources............................11

2. Yearly and seasonal geometric mean TP records in surface water..................11

3. Volumetric basis of mean soil TP per unit area in marl soil and peat soil in the ENP

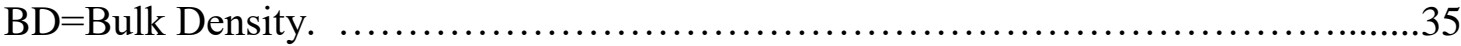




\section{LIST OF FIGURES}

FIGURE

PAGE

1. Map showing the location of Everglades Protection Area (EPA) as composed of the Water Conservation Areas (WCAs) and Everglades National Park (ENP .8

2. Map showing the five transects across the Everglades Protection Area................13

3. Map showing the distribution of sample sites obtained from multiple sources of Soil TP

4. Map showing the distribution and sources of sample sites used for analyzing seasonal variability of surface water TP....

5. Trend of total phosphorus in surface water from 2008 to 2016 at WCA1 transect.

$(\mathrm{A}, \mathrm{B}, \mathrm{C})$ comparison of model fit among years at transect 1 (curve fit: $\left.\mathrm{r}^{2}=0.99, \mathrm{p}=0.10\right)$

6. Trend of total phosphorus in surface water from 2008 to 2016 at WCA1 transect.

(A, B, C) comparison of model fit among years at transect 2 (curve fit: $\left.\mathrm{r}^{2}=0.95, \mathrm{p}=0.1\right)$.

7. Trend of total phosphorus in surface water from 2008 to 2016 at WCA2 transect. (A, B, C) represents comparison of model fit among years at transect 3 (curve fit: $\left.\mathrm{r}^{2}=0.97, \mathrm{p}=0.03\right)$

8. Trend of total phosphorus in surface water from 2008 to 2016 at WCA3 transect. $(\mathrm{A}, \mathrm{B}, \mathrm{C})$ represents comparison of model fit among years at transect 4 (curve fit: $r 2=0.99, \mathrm{P}=0.001)$.

9. Trend of total phosphorus in surface water from 2008 to 2016 at ENP transect. $(\mathrm{A}, \mathrm{B}, \mathrm{C})$ represents comparison of model fit among years at transect 5 . The curve didn't fit in any of the years $(\mathrm{p}=1.0)$.

10. The distribution of TP concentrations in EPA soil from 2004 to 2014. Independent Kruskal-Wallis test found no significant difference at $95 \%$ Confidence Interval $(\mathrm{p}=0.205)$ among the study year.

11. The empirical CDF curve showed the probability function of soil TP observed in 2004 to 2014.

12. Concentration of soil TP in 2004 across the EPA (Color shows the ranges of $\mathrm{TP} \mu \mathrm{g} / \mathrm{g}$ dry weight soil).... 
13. Concentration of soil TP in 2005 across the EPA (Color shows the ranges of

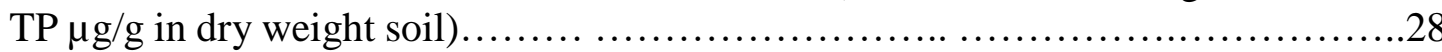

14. Concentration of soil TP in 2013 across the EPA (Color shows the ranges of $\mathrm{TP} \mu \mathrm{g} / \mathrm{g}$ in dry weight soil).....

15. Concentration of soil TP in 2014 across the EPA (Color shows the ranges of $\mathrm{TP} \mu \mathrm{g} / \mathrm{g}$ in dry weight Soil).....

16. Distribution of soil TP concentrations with distance from the inflow canal boundaries throughout the period 2004 to 2014 across the EPA

17. Distribution of soil TP in WCA1 from 2004 to 2014. Independent sample KruskalWallis test showed both the significant difference of soil TP among the study years

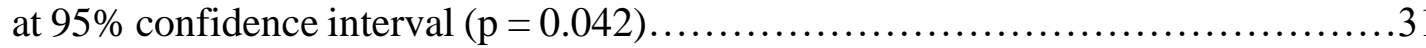

18. Distribution of soil TP in WCA2 from 2004 to 2014. Independent sample KruskalWallis test showed both the significant difference of soil TP among the study years at $95 \%$ confidence interval $(\mathrm{p}=0.944)$.

19. Distribution of soil TP in WCA3 from 2004 to 2014. Independent sample KruskalWallis test determined the significant difference of soil TP among the study years

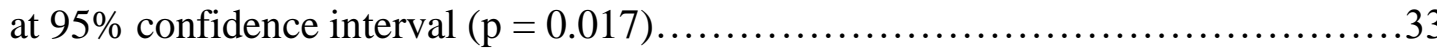

20. Distribution of soil TP in ENP from 2004 to 2014. Independent sample KruskalWallis test didn't find any significant difference of soil TP among the study year at $95 \%$ confidence interval $(\mathrm{p}=0.580)$

21. Distribution of TP concentration in peat and marl soil at ENP throughout the year from 2004 to 2014. Independent sample Mann-Whitney test determined the significant of soil TP among the study years at $95 \%$ confidence interval $(\mathrm{p}=0.03) \ldots 35$

22. Annual GM TP concentrations in surface water in dry and wet season across the EPA from 2004 to 2016. Independent sample Mann-Whitney test determined the significant difference between the seasons at $95 \%$ confidence interval $(\mathrm{p}=0.000) .36$

23. Seasonal GM averaged TP in the EPA from 2004 to 2016

24. Seasonal variability of annual GM TP in the WCA1 from 2004-2016. Independent Kruskal-Wallis test found the significant difference between wet and dry season throughout the study year at $95 \%$ confidence interval $(\mathrm{p}=0.000$. .38

25. Comparison of annual GM TP for dry and wet season at WCA2 from 2004 to 2016. Independent sample Mann-Whitney test didn't result any significant difference of 
water TP in dry and wet season throughout the year at $95 \%$ confidence interval

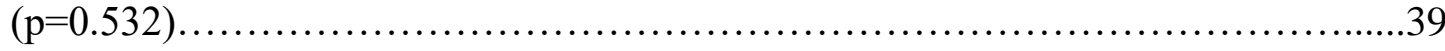

26 Comparison of annual GM TP for dry and wet seasons at WCA3 from 2004 and 2016 Independent sample Mann-Whitney test didn't find any significant difference in water TP between the dry and wet seasons at the $95 \%$ confidence interval

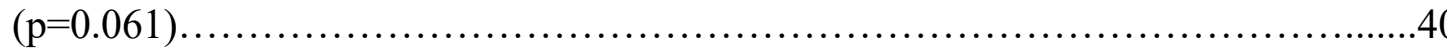

27. Comparison of annual GM TP for dry and wet season at ENP from 2004 to 2016. Independent sample Mann-Whitney test didn't find any significant difference of Water TP in dry and wet season throughout the year at $95 \%$ confidence interval $(\mathrm{p}=0.109)$..... 


\section{ABBREVIATIONS AND ACRONYMS}

ACOE

BMP

$\mathrm{CDF}$

CERP

EAA

ENP

EPA

FCE LTER

GIS

GM

LNWR

QA/ QC

REMAP

SAMP

SFWMD

SREC

SRS

STAs

$\mathrm{TP}$

TS

USEPA

WCAs
Army Corps and Engineers

Best Management Practice

Cumulative Distribution Function

Comprehensive Everglades Restoration Plan

Everglades Agricultural Area

Everglades National Park

Everglades Protection Area

Florida Coastal Everglades Long-term Ecological Research

Geographic Information System

Geometric Mean

Loxahatchee National Wildlife Refuge

Quality Assurance/ Quality Control

Regional Environmental Monitoring and Assessment Program

Regular Collected Samples

South Florida Water Management District

Southeast Environmental Research Center

Shark River Slough

Stormwater Treatment Areas

Total Phosphorus

Taylor Slough

United States Environment Protection Agency

Water Conservation Areas 


\section{INTRODUCTION}

The Central and South Florida Flood Control (C \& SF) project was implemented in 1948 by the United States Army Corps of Engineers (ACOE) to provide flood control and water supply for South Florida's emerging economy. While accomplishing its overall goals, the C\&SF project triggered rapid and drastic changes to the natural hydrologic pattern of the entire Everglades ecosystem by building compartments and impoundments surrounded by dikes and levees as well as canals that drained fresh water to the coasts (Light and Dineen, 1994). The draining of the Everglades allowed for the expansion of urban and agricultural development, reducing the original size of the historic Everglades by half (Perry 2004). All of those changes resulted in a cascade of environmental disruptions throughout the Everglades landscape (Davis and Ogden 1994). As the Everglades ecosystem was naturally oligotrophic (Noe et al. 2001), long term agricultural and industrial practices altered the ecosystem functions through anthropogenic inputs of nutrients and minerals (Gaiser 2009). Due to phosphorus $(\mathrm{P})$ enrichment, the marsh plant communities become dominated by Typha (cattails), whose rapid expansion resulted in degrading the quality of marsh habitat by making these areas less suitable for fish and wading birds (Harvey et al. 2014). Recognizing these detrimental impacts the remaining Everglades has been designated as the Everglades Protection Area (EPA).

Although protected, the EPA is characterized by degraded water quality (Sklar et al. 2002) shifting vegetation, declining wildlife populations, and loss of peat soil (Davis 1994; Noe et al. 2001). Subsequently, the Everglades is a target of one of the world's largest restoration actions known as the Comprehensive Everglades Restoration Plan (CERP), 
enacted in 2000 by the US Congress (Schade-Poole and Moller 2016, Osborne et al. 2011). The main goal of CERP is to restore the water quantity available throughout the year as well as improve the water delivery time to the Everglades as close as possible to its historic water flow (Perry 2004). One of the important mandates of the CERP was to implement agricultural best management practices (BMPs) and constructed wetlands known as stormwater treatment areas (STAs), to reduce the amount of P from the Everglades agricultural area (EAA) runoff prior to discharging the water to EPA (Sklar et al. 2005). Most of the CREP's current planning projects have focused on improving water storage, restoring historic hydrologic conditions in the remnant natural Everglades and removing excess P; a benchmark of water quality (Perry 2004).

In the 16 years since CERP was enacted, advances have been made in reducing P loading from agricultural areas and its subsequent concentration lowering in downstream waters (Davison et al., 2017). The agricultural BMPs and Everglades STAs have reduced approximately $62 \%$ of the Total Phosphorus (TP) loading in the last two decades (Davison et al. 2017). However, despite the reduction, there are still areas in the EPA where TP concentrations are higher than class III Numerical water quality criterion which has been set as $10 \mu \mathrm{g} / \mathrm{L}$ as long term geometric mean concentrations in Everglades marshes (Payne et al. 2003). The $10 \mu \mathrm{g} / \mathrm{L}$ TP criterion was set by Everglades Forever Act (EFA) and incorporated in rule under 62.302-540 Florida Administrative Code F.A.C. (Julian II 2016). The test of TP criterion is assessed only for impacted and un-impacted areas over the network of 58 spatially explicit monitoring stations in Water Conservation Areas (WCAs) whereas the Everglades National Park (ENP) has already achieved this P criterion (Julian 
2016). One student determined that TP concentrations in WCAs have decreased more from 2004 to 2014 than in previous decades but were still above the legal water quality criterion (Julian et al., 2015). According to Zapata et al. (2012), the long term (1995-2007) declines were observed in TP concentrations in WCA1, but increased over the short term (20032007) in other areas of the EPA. Zapata et al. (2012) found that TP concentrations decreased along a north to south spatial gradient with the highest TP levels observed in the northern WCAs and the lowest levels in ENP. Furthermore, there was a strong seasonal variability of TP with higher concentrations observed in the dry season (Zapata et al. 2012). Extreme weather conditions such as hurricanes and droughts posed a significant threat to the performance of the STAs in regarding the retention capacity of TP from storm water runoff delivered to EPA (Chen et al. 2015).

Combined, the TP of surface water and soil are major indicators of ecosystem health of a wetland system. In the Everglades, soils can act as a sink or source of significant nutrients especially P (Osborne et al. 2011). Generally, nutrient inputs to wetlands are stored primarily in soils and such soils work as a long-term integrator of ecosystem changes of hydrology, water quality, and/or vegetation, and therefore, provide a substantial metric for monitoring environmental conditions (Debusk et al. 1994; Doren et al. 1997; Reddy et al. 2005). As a combined indicator of $P$ loading to the wetland ecosystem, the top soil ( 0 to 10 cm) TP concentration is commonly used to demonstrate eutrophication (Qian et al. 2004). As a result the spatial distribution of soil nutrients can be used to assess the long term nutrient impact in order to track the ecosystem health. In addition, the rate of spatialtemporal changes in overlying water quality is much faster than changes of soils properties (Reddy et al., 1995) and so restoration of water quality in a region might take some time in 
improving soil quality within the same area. Understanding the legacy effect of soil is critical (Reddy et al. 2005) and needed in assessing long-term Everglades restoration.

Canalization of the Everglades natural ecosystem resulted in two important effects (Childers et al. 2003). First, the hydrologic modification divided the Everglades into several individual impoundments (e.g. WCAs) that were designed to store water disturbing the natural flow of water from the WCAs in the north to ENP in the south. Second, as a result of compartmentalization, the remaining Everglades received surface water mostly via point sources from canal discharge points as opposed to a more diffuse flow across a wetland (Childers et al. 2003). There have been significant differences observed in the TP concentration of sediments in canals versus marsh sediments with canal sediments tending to have higher concentrations of TP than marshes (Wang et al. 2011). The primary source of $\mathrm{P}$ in drainage canals are from land use application of agricultural chemicals and oxidation of soils within the EAA (Das et al. 2012). Das et al. (2012) recognized that the canals collecting sediments from the EAA can be easily transported to downstream areas of the EPA. As the Everglades is a high alkaline wetland, inorganic $\mathrm{P}$ is often immediately immobilized by adsorbing to calcium carbonate (Childers et al. 2017). Continued adsorption of $\mathrm{P}$ to soils over time resulted in an increasing trend of TP found in Everglades soil. Previously there were several studies conducted to investigate the P enrichment in Everglades soil (Noe et al. 2002). The first spatially intensive study to document TP in Everglades soils was conducted by the U.S Environmental Protection Agency (USEPA) and became known as Regional Environmental Monitoring and Assessment Program (REMAP) (Osborne et al. 2011). Several REMAP studies were conducted in different phases starting in 1993 with its latest phase completed in 2014. Scheidt and Kalla (2007) 
reported that the during 2005, about 24\% of the Everglades REMAP sampling sites had soil TP greater than $500 \mu \mathrm{g} / \mathrm{g}$ soil, which was considered as "impacted soils" defined by 62-302.540 Florida Administrative Code (F.A.C) (Qian et al. 2004). The CERP's restoration goal was to limit TP concentration below $400 \mu \mathrm{g} / \mathrm{g}$ for Everglades soil but about 49\% EPA were above this restoration limit observed in 2005 (Kalla and Scheidt 2007). The amount of REMAP sampling sites with soil TP concentrations in both ranges were increased from 1995 to 2005 (Kalla and Scheidt 2007).

Generally, P has a complex cycle between water, plants and soil, such that when it enters into a water body it can recycle in place and remain in the marsh or move slowly downstream creating a cascading impact (Gaiser et al. 2005). This ecological cascade stems with degrading algal and plant communities (Periphyton) leading to an increase in soil P concentration, an alteration of a diverse native plant community to a dense cattail monoculture and ultimately resulting in the loss of historical Everglades ridge-and-slough habitat (Naja et al. 2017). The detrimental cascading effect on Everglades ecosystem function is related to the total $\mathrm{P}$ (TP) concentrations of water inflow, the inflow rate and the distance from the discharge point (Gaiser 2006). In order to control the P loading to downstream Everglades, it is important to track the long term changes of TP in both Everglades soil and surface water from the inflow canal structures. Childers et al. (2003) found the highest TP concentrations in Everglades soil was located within one kilometer of an inflow canal. In general the highest TP concentrations in surface water and soil have been caused by nutrients and mineral inputs through canals (Bruland et al. 2007). Both Surrat et al. (2014) and Zapata et al. (2012) mentioned the highest TP increases in areas adjacent to the Tamiami canals along the L-5 canal especially in the southern Everglades. 
As Everglades restoration has approached 15 years since the inception of CERP, there is a need to assess its progress across the ecosystem. The goal of the present research was to assess the long term trend of TP concentrations in water and soil across the EPA. The goal was obtained by gathering available TP data for soil and water collected across the EPA from numerous investigators. Available data from 2004 to 2014 were collected for soils and from 2004 to 2016 for water to understand a decade of trends. In addition, the long term data were investigated in both the dry and wet seasons to track any seasonal variability of TP in surface water.

Three hypotheses were tested: (I) Decreasing concentrations of TP in surface water were correlated with distance downstream of a discharge point; (II) Concentrations of TP in soils increased with time across the EPA especially near inflow canals; and (III) Concentrations of TP in surface water throughout the EPA decreased with time between 2004 and 2016 but concentrations varied seasonally. The result of this research might be used to assess the effects of the Everglades restoration efforts by quantifying the long term TP concentrations in soil and water in EPA. 


\section{METHODS}

\subsection{Study Area}

The EPA consists of the three WCAs and ENP (Figure 1). Figure 1 shows the location of all four compartments as well as the STAs (north of the WCAs), main canals and levees. The historic Everglades was previously a continuous marsh network from the North of lake Okeechobee to all the way down to the Florida Bay where water mostly flowed by sheet flow. Currently, the EPA mostly receives water from upstream EAA canals passed through the STAs. The topmost compartment of EPA is Loxahatchee National Wildlife Refuge (LNWR) aka WCA1 and comprises about $590 \mathrm{~km}^{2}$ which mostly receives water directly rainfall and surrounding canals. In addition to rainfall the WCA2 receives water from WCA1 through water control structures as well as EAA runoff through STAs. The WCA3 lies immediately south of the WCA2 and receives water from upstream water controlled structures and EAA runoff through the L-28 canal. The southern Everglades ENP receives the majority of its water directly from rainfall (Saha et al. 2012) as well from WCA3 via the discharge points along Tamiami canal. 


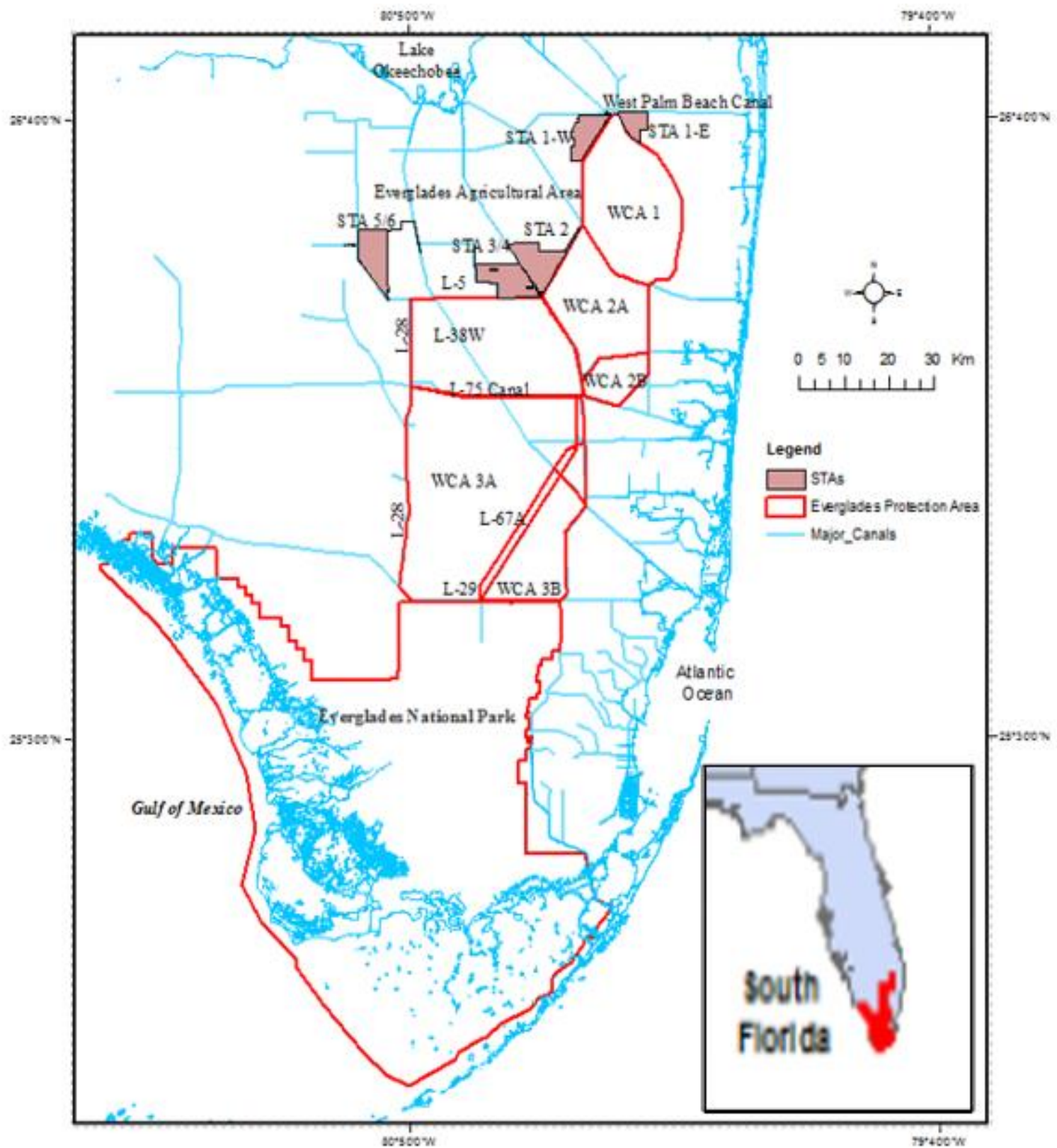

Figure 1: Map showing the location of Everglades Protection Area (EPA) as composed of the Water Conservation Areas (WCAs) and Everglades National Park (ENP). 


\subsection{Data Acquisition}

The TP data of surface water were gathered from multiple sources including the South Florida Water Management District (SFWMD) DBhydro web database, Florida Coastal Everglades Long Term Ecological Research (FCE-LTER) and the soil nutrient data were collected from United States Environmental Protection Agency's (USEPA) Regional, Environmental Monitoring and Assessment (REMAP), Everglades Soil Mapping (ESM) as well as personal contact of related research professionals. The TP data for surface water were collected from SFWMD DBhydro web database and FCE-LTER. When downloading the data from DBhydro, only regularly collected samples (SAMP) were used to conduct the analysis. As per DBhydro metadata, the regular samples were collected monthly by grab method throughout the year from 2004 to 2016 for SFWMD monitoring stations across the EPA. In some stations, the regular water samples were obtained three or four times (weekly) in a month meaning that some stations had a higher frequency of samples then others. All flagged and field quality controlled values were excluded to avoid the duplication of data. In order to maintain the quality assurance/ quality control (QA/QC) the method detection limit for water TP was fixed at $2 \mu \mathrm{g} / \mathrm{L}$ by the SFWMD. The TP data for ENP Shark River Slough (SRS) and Taylor Slough (TS) transects were downloaded from FCE LTER data repository. The FCE surface water data collection methods are explicitly explained in FIU Southeast Environmental Research Center (SERC) water quality protocol (FCE LTER website). Triplicate samples were averaged and replaced by a single value. To maintain consistency between the FCE and SFWMD data sets, only TP data at or above $2 \mu \mathrm{g} / \mathrm{L}$ were used for further analysis. 
The TP data for soils were gathered from multiple sources such as ESM, USEPA-REMAP and FCE-LTER respectively for 2004, 2005, 2013 and 2014. As a combined indicator of P loading to the wetland ecosystem (Qian et al. 2004), only values with the depth of (0 to 10 $\mathrm{cm})$ soil were gathered for further analysis. As the data were collected from multiple sources, separate methods were used to collect the soil samples. The ESM data were collected by University of Florida wetland biogeochemistry lab by Reddy et al. (2005) for 0 to $10 \mathrm{~cm}$ top soils by utilizing stratified sample design (Osborne et al. 2011). Any triplicate samples collected for same sites averaged and into a single value and the details data collection process were adopted from (Corstanje et al. 2016). The REMAP samples were collected by USEPA for the same 0 to $10 \mathrm{~cm}$ top soil by using probability based sampling approach; meaning every member of a population has known and equal chance to be selected. The FCE LTER data for ENP soils were also collected for 0 to $10 \mathrm{~cm}$ top soil for 17 sites along SRS and TS transects.

\subsection{Database Compilation}

A comprehensive database including approximately 35,000 records (explained in section 2.2) for soil and surface water TP have been developed in Microsoft Excel (Table 1). Data were parameterized for units, season and date of collections before putting together in the database. The dry season was defined as data collected in the months of November to April, and wet season months was defined as May through October. In order to conduct the spatial and temporal analysis on multiple sources data, the units for soil and surface water TP were standardized respectively $\mu \mathrm{g} / \mathrm{g}$ in dry weight soil and $\mu \mathrm{g} / \mathrm{L}$ for data coherency. To conduct the data analysis, the monthly collected surface water TP records from DBhydro were 
averaged into annual geometric mean (GM) for the sites that had TP data samples at or above six months between wet and dry seasons throughout the year from 2004 to 2016 .

\begin{tabular}{|l|r|r|r|}
\hline \multicolumn{4}{|c|}{ Number of Records Collected for soil and surface water } \\
\hline Sources & Surface water TP $\mu \mathrm{g} / \mathrm{L}$ & Soil TP $\boldsymbol{\mu g} / \mathrm{g}$ & Grand total \\
\hline SFWMD & 32863 & & 32863 \\
\hline ESM & & 940 & 940 \\
\hline REMAP & & 389 & 389 \\
\hline FCE-LTER & 1105 & 168 & 1273 \\
\hline Total & 33968 & 1497 & 35465 \\
\hline
\end{tabular}

Table 1: Number of monthly sample records collected for study sites across the entire EPA for water and soil based on multiple sources.

The new database including about 1500 (Table 2) (Appendix 1) records of surface water TP was developed to conduct the long-term trend analysis of water TP across the EPA. For soil trend analysis, the original TP data were used that obtained at each sites (Table 1) from multiple sources for the year 2004, 2005, 2013, and 2014.

\begin{tabular}{|r|r|r|r|r|r|}
\hline \multicolumn{7}{|c|}{ Number of Records at sites } \\
\hline Year & WCA1 & WCA2 & WCA3 & ENP & \multicolumn{1}{l|}{ Total } \\
\hline $\mathbf{2 0 0 4}$ & 25 & 12 & 24 & 17 & 78 \\
\hline $\mathbf{2 0 0 5}$ & 32 & 12 & 25 & 20 & 89 \\
\hline $\mathbf{2 0 0 6}$ & 21 & 12 & 24 & 20 & 77 \\
\hline $\mathbf{2 0 0 7}$ & 28 & 28 & 28 & 21 & 105 \\
\hline $\mathbf{2 0 0 8}$ & 39 & 23 & 33 & 23 & 118 \\
\hline $\mathbf{2 0 0 9}$ & 39 & 23 & 31 & 24 & 117 \\
\hline $\mathbf{2 0 1 0}$ & 39 & 30 & 32 & 24 & 125 \\
\hline $\mathbf{2 0 1 1}$ & 25 & 29 & 27 & 20 & 101 \\
\hline $\mathbf{2 0 1 2}$ & 38 & 34 & 32 & 23 & 127 \\
\hline $\mathbf{2 0 1 3}$ & 43 & 35 & 32 & 20 & 130 \\
\hline $\mathbf{2 0 1 4}$ & 43 & 35 & 31 & 23 & 132 \\
\hline $\mathbf{2 0 1 5}$ & 42 & 22 & 32 & 20 & 116 \\
\hline $\mathbf{2 0 1 6}$ & 42 & 35 & 35 & 18 & 130 \\
\hline Total & 456 & 330 & 386 & 273 & $\mathbf{1 4 4 5}$ \\
\hline
\end{tabular}

Table 2: Yearly and seasonal geometric mean TP records in surface water 


\subsection{Data Analysis}

\subsubsection{Distance gradient analysis in surface water TP along EPA transects}

To address the first hypothesis, five transects (Figure 2) were selected from canal discharge points to down gradient marsh stations across the EPA. On the basis of data consistency throughout the year for each sites, the TP data were selected for three different years (2008, 2012, and 2016) for all transect stations to compare the spatial and temporal changes of TP among all each individual transects. By using Geographic Information System (GIS) proximity tools (near) the distance of each station to its discharged point was determined for all transects (Appendix 2). Data were plotted as TP $(\mu \mathrm{g} / \mathrm{L})$ versus distance from the discharge point (d) and fitted to the following exponential decay model (Childers et al. 2003).

$$
\mathbf{C}=\mathbf{b}+\mathbf{C o}^{*} \exp (-\mathbf{k d})
$$

Where $\mathrm{C}$ is the concentration of surface water TP at a given location, Co is an estimation of water $\mathrm{P}$ at the transect in proximity to the inflow canal (discharge point), $\mathrm{k}$ is the slope of the exponential curve which represents the rate of concentration changes (decline), and $\mathrm{d}$ represents the distance (in $\mathrm{km}$ ) from the transect inflow canal stations, and $\mathrm{b}$ is a constant that predicts the background concentrations of TP in water for un-impacted conditions (Childers et al. 2003). Statistical software Sigmaplot 14 and SPSS 24 were used to fit the model for each transect from 2008 to 2016. Then the fitted model were compared among the years. The principle component errors were perform to compare between years in order to determine the significant difference of rate constant found in individual transects. Though the equation was originally used to analyze the distance gradient of TP in soil by 
Childers et al (2003) to predict the background TP concentration for un-impacted areas, we used a similar approach in fitting this model to water TP data.

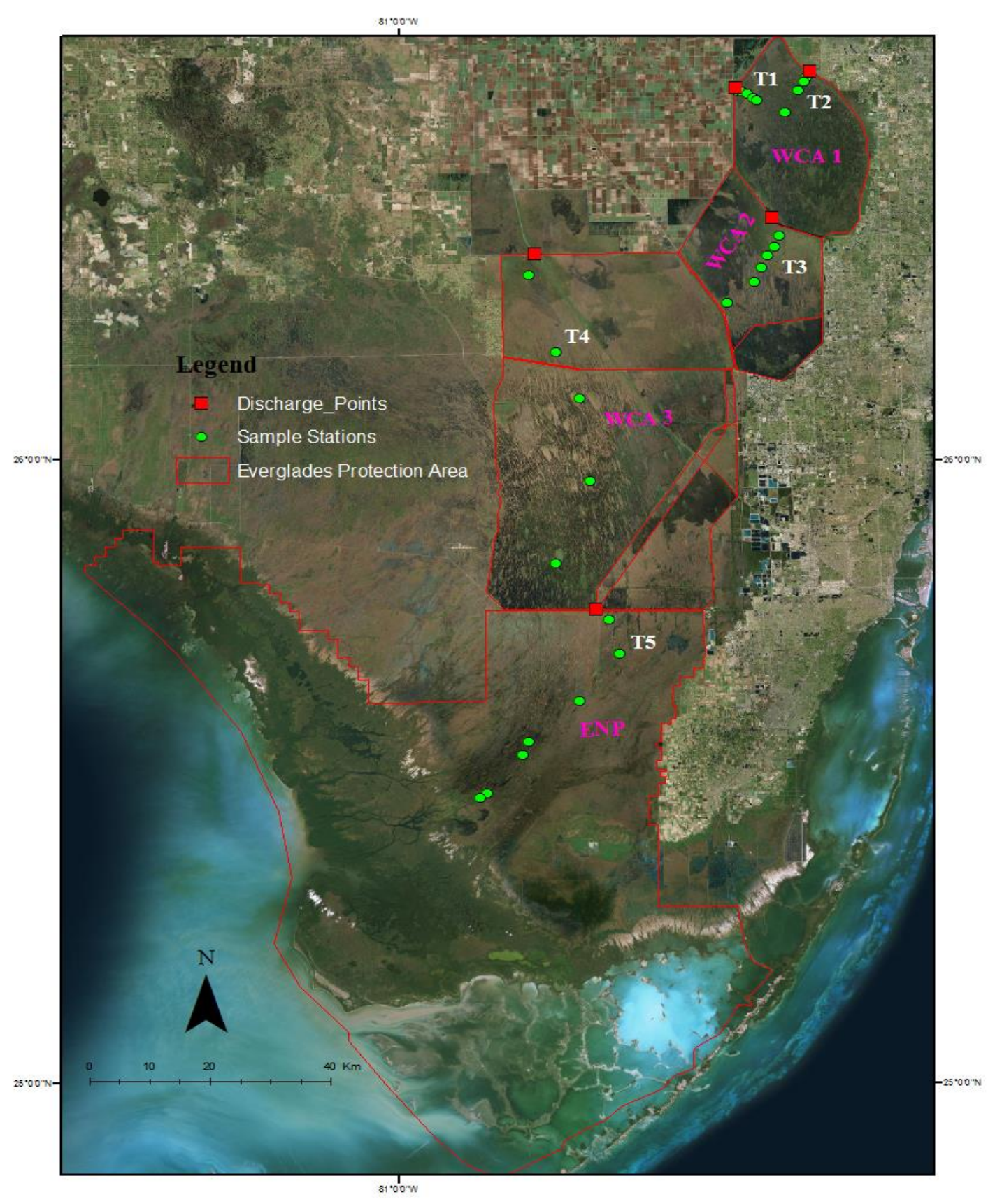

Figure 2: Map showing the five transects across the Everglades Protection Area 


\subsubsection{Soil TP Distribution Analysis}

To address the second hypothesis, both GIS and statistical analysis were used to assess the spatial distribution of changes in TP concentrations in soils from 2004 to 2014 (Figure 3). The TP data were categorized into six different ranges $(<100,100-200,200-300,300-400$, 400-500, and $>500 \mu \mathrm{g} / \mathrm{g}$ ) by using GIS map symbology tools to visualize the TP distributions for all individual years across the EPA. The GIS Proximity analysis (near) tool was used to estimate the nearest distance of all sample sites from the inflow canal boundaries to determine the highest TP concentrations in close proximity to the inflow canals. The non-parametric Wilcoxon Rank Sum test was performed to compare the TP concentrations among all years from 2004 to 2014 . Both sigma plot 14.0 and SPSS 24.0 software were used to conduct this analysis. Also, the empirical cumulative distribution function (CDF) model was produced in Minitab 17.0 for all individual hydrologic units (WCAs, ENP) for all years to compare the changes of TP thereof and justified the significant level acquired from nonparametric test.

Moreover, the TP concentration were analyzed individually in peat and marl soil for Everglades National Park. As the increasing organic matter in sediment can increase in organic P for making the $\mathrm{P}$ bioavailable for plants (Wang and Ouyang 2011), there is a substantial TP difference observed in Everglades peat and marl soil. Box and whisker plot and nonparametric Mann-Whitney test were conducted to visualize the TP concentrations vs mass to compare the changes of TP in both soils for ENP. 


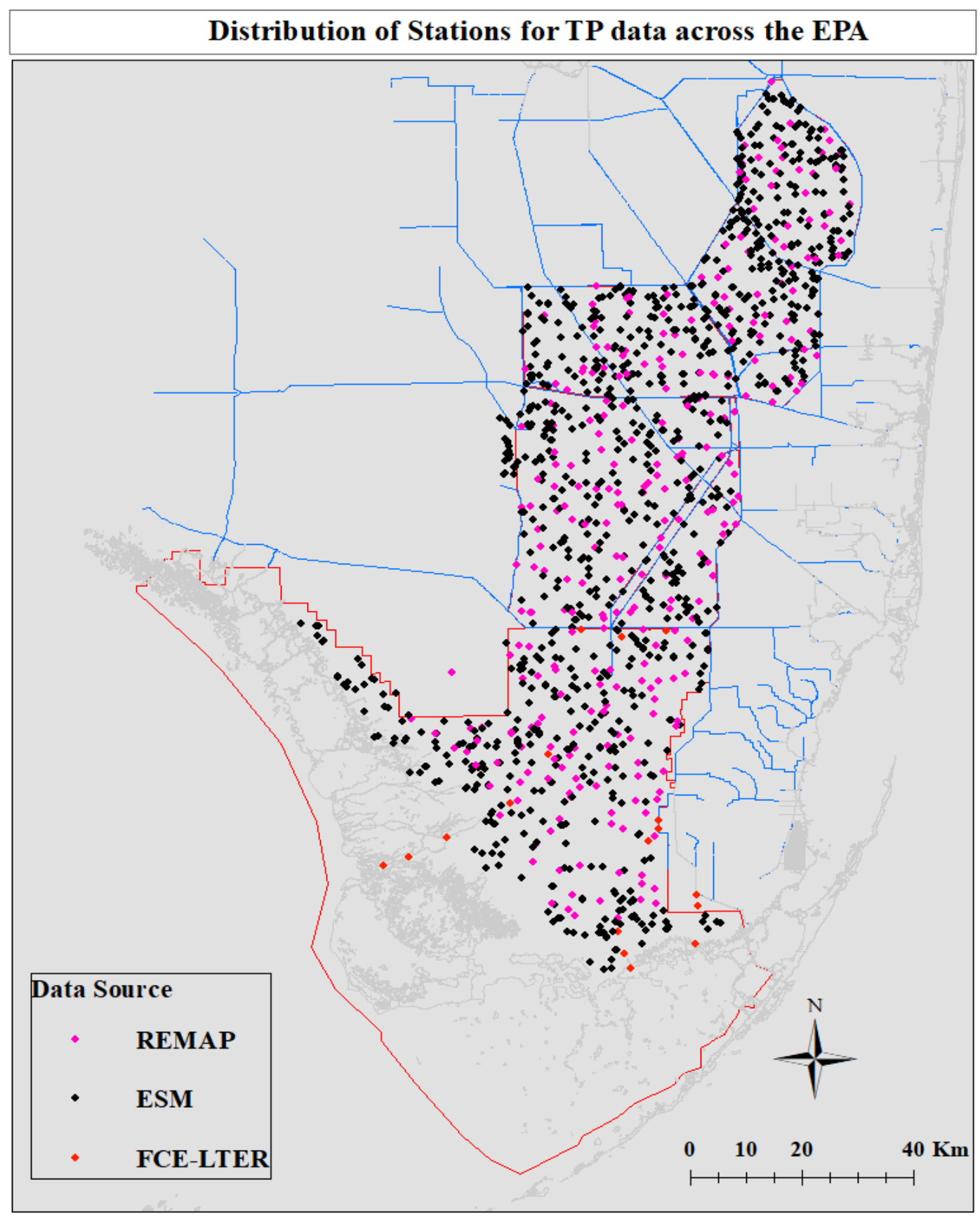

Figure 3: Map showing the distribution of sample sites obtained from multiple sources of Soil TP 


\subsubsection{Seasonality analysis of surface water TP}

To address the third hypothesis, the surface water TP data from 2004 to 2016 were analyzed

yearly and seasonally (Figure 4). The data were grouped into each hydrologic area (e.g. WCAs, ENP) and the both annual GM for each site and annual GM average of TP for each area was determined for the study periods. For finding seasonality, the water TP data were categorized as dry and wet season to examine the seasonal TP distributions changes throughout the hydrologic gradient of EPA. By using Microsoft excel 2016, a summary dataset was created for surface water TP by geometric averaging values per season, year and location (Appendix 1). The time series analysis were conducted to determine the seasonal trend of TP concentration in dry and wet seasons. Box and whisker (gg) time series plots were produced to visualize the distributions for TP changes throughout the year from 2004 to 2016 in entire EPA. Non-parametric Mann-Whitney test was conducted in SPSS to determine the seasonal difference of TP in surface water throughout the period across the entire EPA as well as each hydrologic units. 


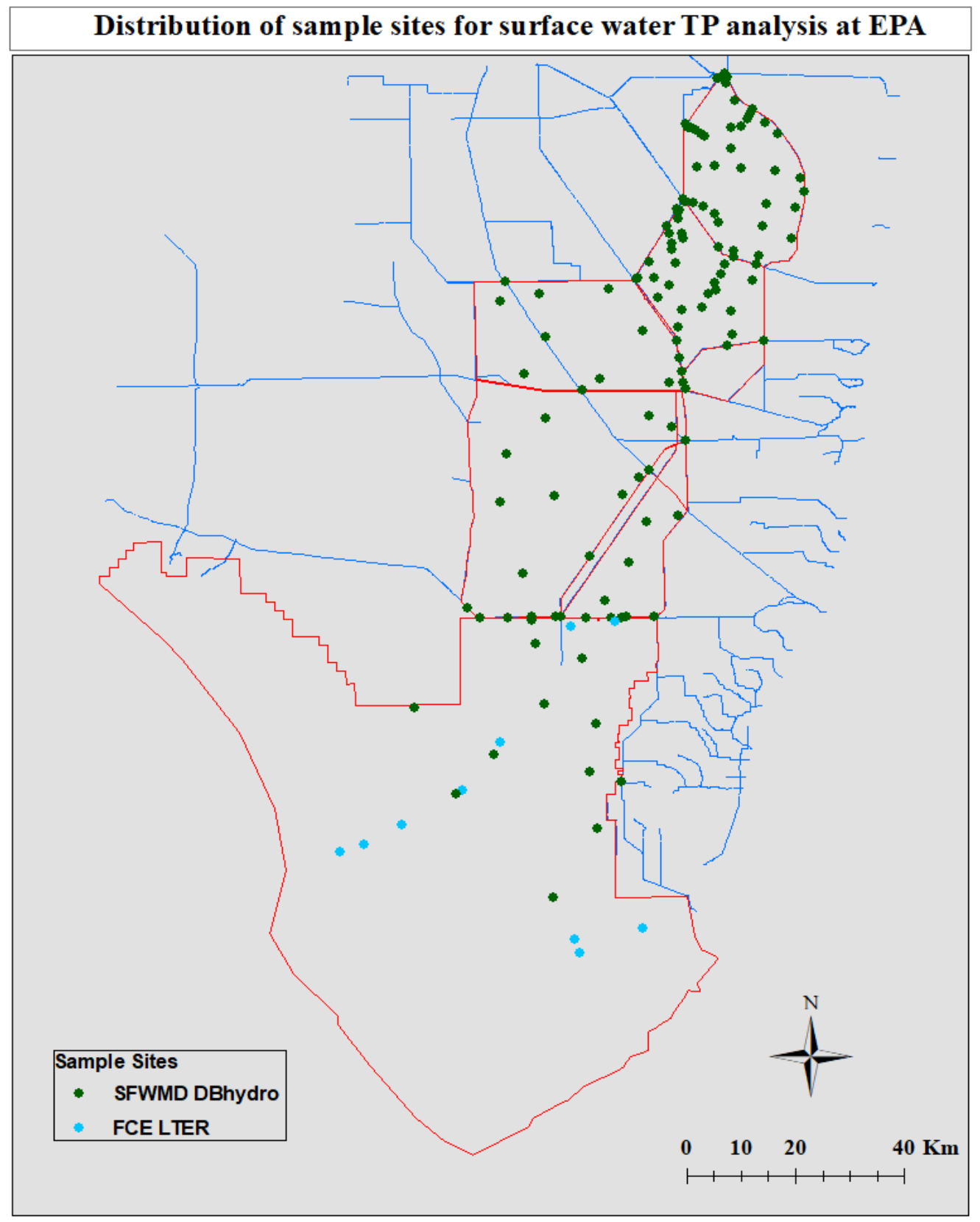

Figure 4: Map showing the distribution and sources of sample sites used for analyzing seasonal variability of surface water TP. 


\section{RESULTS}

\subsection{Distance gradient analysis in surface water TP along EPA Transects}

In the first hypothesis, there was a significant decrease found in water TP concentration downstream of discharge points from 2008 to 2016 throughout the EPA. The highest TP concentrations (10 to $35 \mu \mathrm{g} / \mathrm{L})$ were found at all sites within the first 1 kilometer $(\mathrm{km})$ from the discharge points to downstream marsh areas. The prediction for TP concentrations for un-impacted areas were between 3.9 to $9.2 \mu \mathrm{g} / \mathrm{L}$ which is less than class III water quality criterion $(10 \mu \mathrm{g} / \mathrm{L})$ for EPA. As the physiography of northern Everglades is quite uneven than the southern Everglades, the model did not seem fit all transects. Following is the description of distance gradient analysis of surface water TP in individual hydrologic units.

\subsubsection{Water Conservation Area 1 Transect}

The first two transects T1 and T2 were selected for WCA1 which ran from west to east and east to west across the refuge from the LOXA 104 and LOXA 135 inflow point respectively with distance 0 to $10 \mathrm{~km}$ approximately. The annual GM of initial TP concentrations at the canal boundary decreased from 24.9 to $12.3 \mu \mathrm{g} / \mathrm{L}$ through the period 2008 to 2016 . However, the TP concentration was still double at less than $1 \mathrm{~km}$ sites than further distance towards the mash areas for both transects. The model predicted the TP concentrations in surface water for un-impacted areas were between $7.1 \mu \mathrm{g} / \mathrm{L}$ to $9.2 \mu \mathrm{g} / \mathrm{L}$ in $\mathrm{WCA} 1$. According to Class III numerical water quality criterion established by EFA and F.A.C. rule 62-302.540, the long term GM TP concentrations in Everglades marsh for individual stations should be less than or equal to $15 \mu \mathrm{g} / \mathrm{L}$ (FDEP, 2005). Our results showed that in WCA1, the predicted GM TP concentrations in water for un-impacted areas are much 
lower than class III water quality criterion. The model predicted that the declining rate of TP concentration for T1 was highest in $2008(\mathrm{k}=-1.6 \mu \mathrm{g} / \mathrm{L} \mathrm{km}-1)$ and lowest in $2012(\mathrm{k}=$ $-0.9 \mu \mathrm{g} / \mathrm{L} \mathrm{km}-1)$ (Figure 5).

In transect 2, higher TP concentrations were observed in $2012(27.7 \mu \mathrm{g} / \mathrm{L})$ than in 2008 $(26.5 \mu \mathrm{g} / \mathrm{L})$ at the $0 \mathrm{~km}$ sites while in 2016 it decreased to $18.6 \mu \mathrm{g} / \mathrm{L}$. However, the highest declining rate of water TP was found in $2012(\mathrm{k}=-1.51 \mu \mathrm{g} / \mathrm{L} \mathrm{km}-1)$ while the lowest was in $2016(\mathrm{k}=-1.1 \mu \mathrm{g} / \mathrm{L} \mathrm{km}-1)$ (Figure 6). The curve fitted well in all years resulting an exponential decline of TP concentrations in surface water with downgrading distance.

\subsubsection{Water Conservation Area 2 Transect}

In transect T3, there was no significant decay in surface water TP found within the first four kilometers from the inflow canal (Figure 7). Beyond $4 \mathrm{~km}$, a significant exponential decay model was fitted to the surface water TP data from 2008 to 2016 . The GM TP concentration at 0 to $4 \mathrm{~km}$ sites varied between 19 to $25 \mu \mathrm{g} / \mathrm{L}$. The declining rate $(\mathrm{k})$ of TP was in between ( 0.2 to $0.3 \mu \mathrm{g} / \mathrm{L} \mathrm{km-1)}$ from 2008 to 2016 .

\subsubsection{Water Conservation Area 3 Transect}

The transect T4 in WCA3 was the longest from north to south extending an approximate distance of $58 \mathrm{~km}$ (Figure 2). The declining rate of TP was significantly higher in 2008 $\left(\mathrm{k}=-0.5 \mu \mathrm{g} / \mathrm{L} \mathrm{km}^{-1}\right)$ than in $2016\left(\mathrm{k}=-0.3 \mu \mathrm{g} / \mathrm{L} \mathrm{km}^{-1}\right)$. The prediction for background water TP concentrations for un-impacted areas were much lower (3.91 to $5.29 \mu \mathrm{g} / \mathrm{L})$ than other transects in the EPA. The TP concentration decreased from 2008 to $2016(9.8$ to $12.9 \mu \mathrm{g} / \mathrm{L})$ at less than $1 \mathrm{~km}$ sites from the discharge points. However, the TP concentrations were almost three times lower than the initial TP at distances from 3 to $58 \mathrm{~km}$ sites indicated a 
significant decay found in throughout the year. Albeit the model fitted well in the year 2008 and 2016 there was a lack of a significant model fit in 2012 because of missing site identified in between the transect (Figure 8).

\subsubsection{Everglades National Park Transect}

The transect T5 were established from the discharge point S333 along the Tamiami Canal and extended approximately $38 \mathrm{~km}$ south into Shark River Slough. In ENP, the geometric mean TP concentrations from the upstream discharge point to the downstream marshes were at or below $10 \mu \mathrm{g} / \mathrm{L}$ (Figure 9). Since there was no spatial gradient at ENP, and the water TP concentration in most of the sites were less than the threshold limit $(<10 \mu \mathrm{g} / \mathrm{L})$ a significant model fit was not obtained for any of the years. 

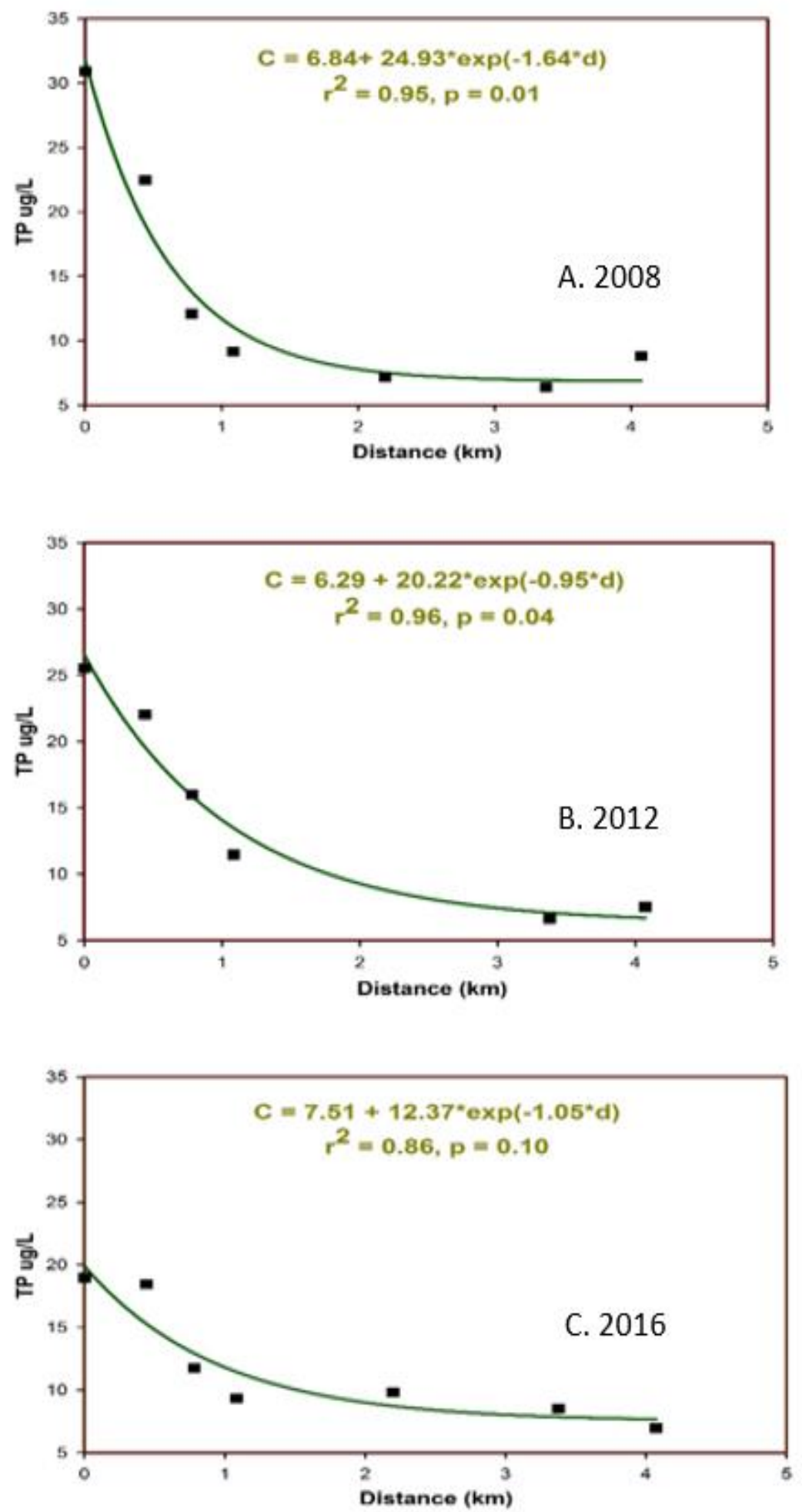

Figure 5: Trend of total phosphorus in surface water from 2008 to 2016 at WCA1 transect. (A, B, C) comparison of model fit among years at transect 1 (curve fit: $r^{2}=0.99, p=0.10$ ) 

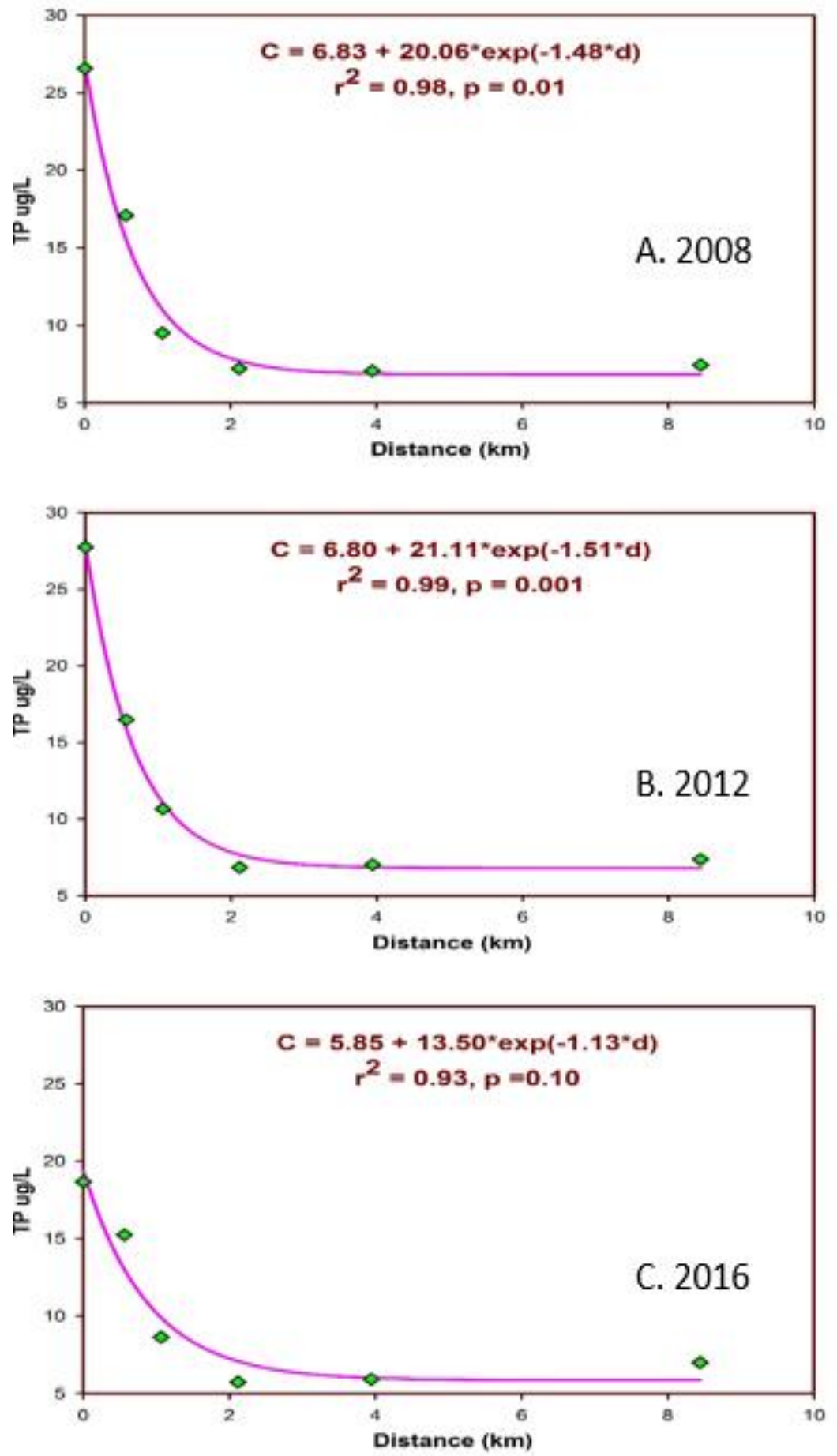

Figure 6: Trend of total phosphorus in surface water from 2008 to 2016 at WCA1 transect. (A, B, C) comparison of model fit among years at transect 2 (curve fit: $\mathrm{r}^{2}=0.95, \mathrm{p}<0.1$ ) 

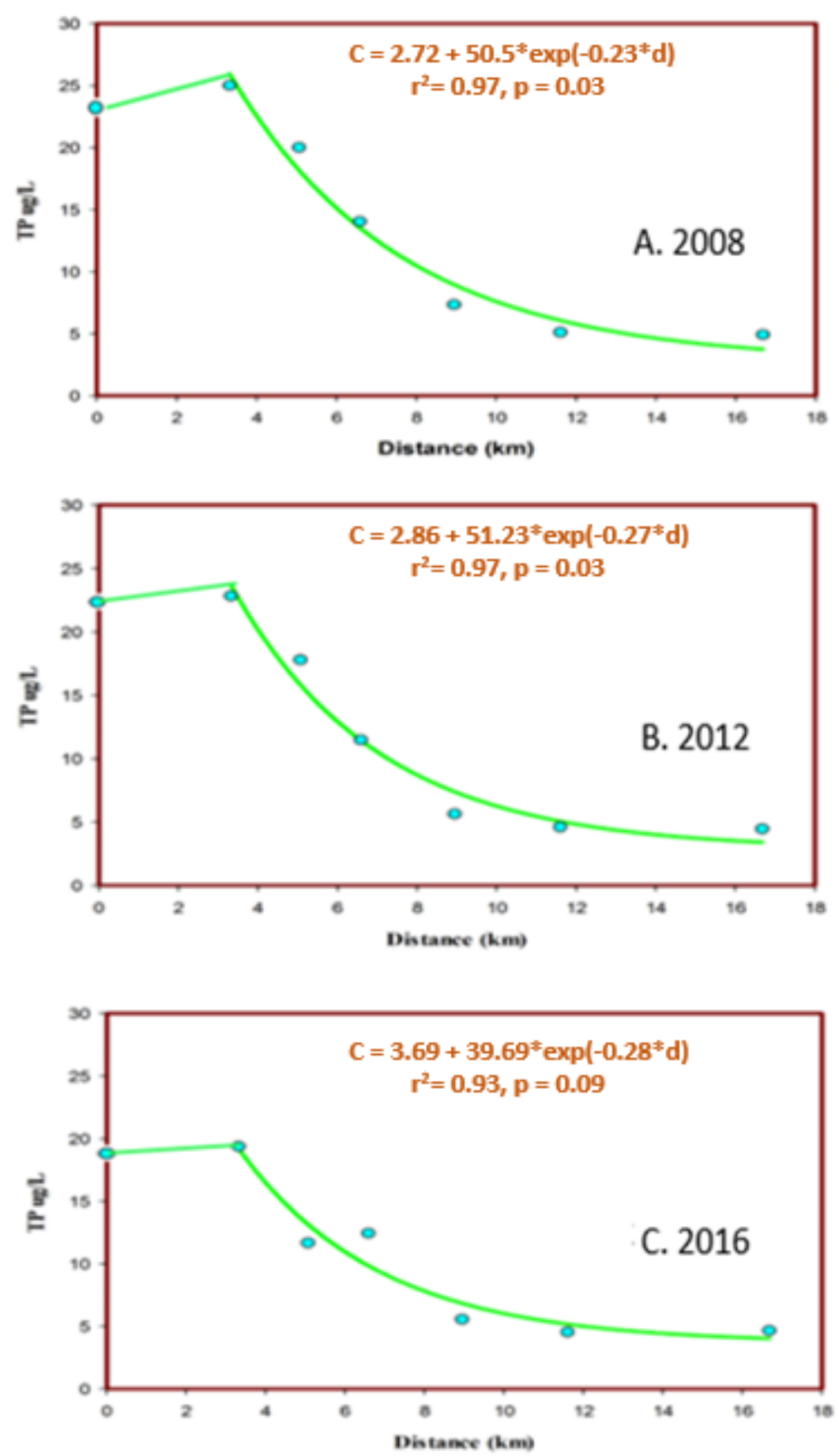

Figure 7: Trend of total phosphorus in surface water from 2008 to 2016 at WCA2 transect. (A, B, C) represents comparison of model fit among years at transect 3 (curve fit: $\mathrm{r}^{2}=0.97, \mathrm{p}=0.03$ ) 

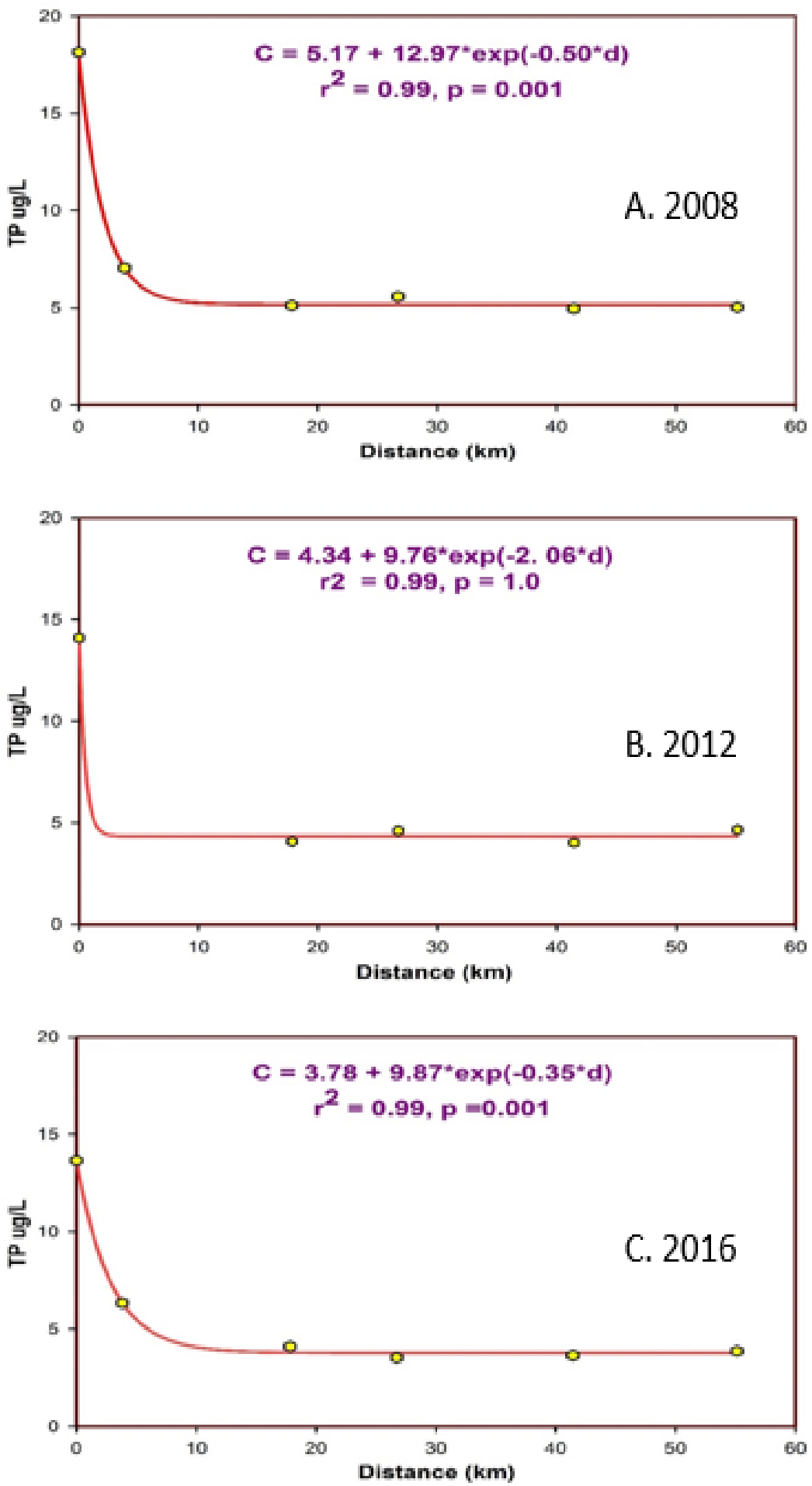

Figure 8: Trend of total phosphorus in surface water from 2008 to 2016 at WCA3 transect. (A, B, C) represents comparison of model fit among years at transect 4 (curve fit: $r 2=0.99, \mathrm{P}=0.001$ ) 

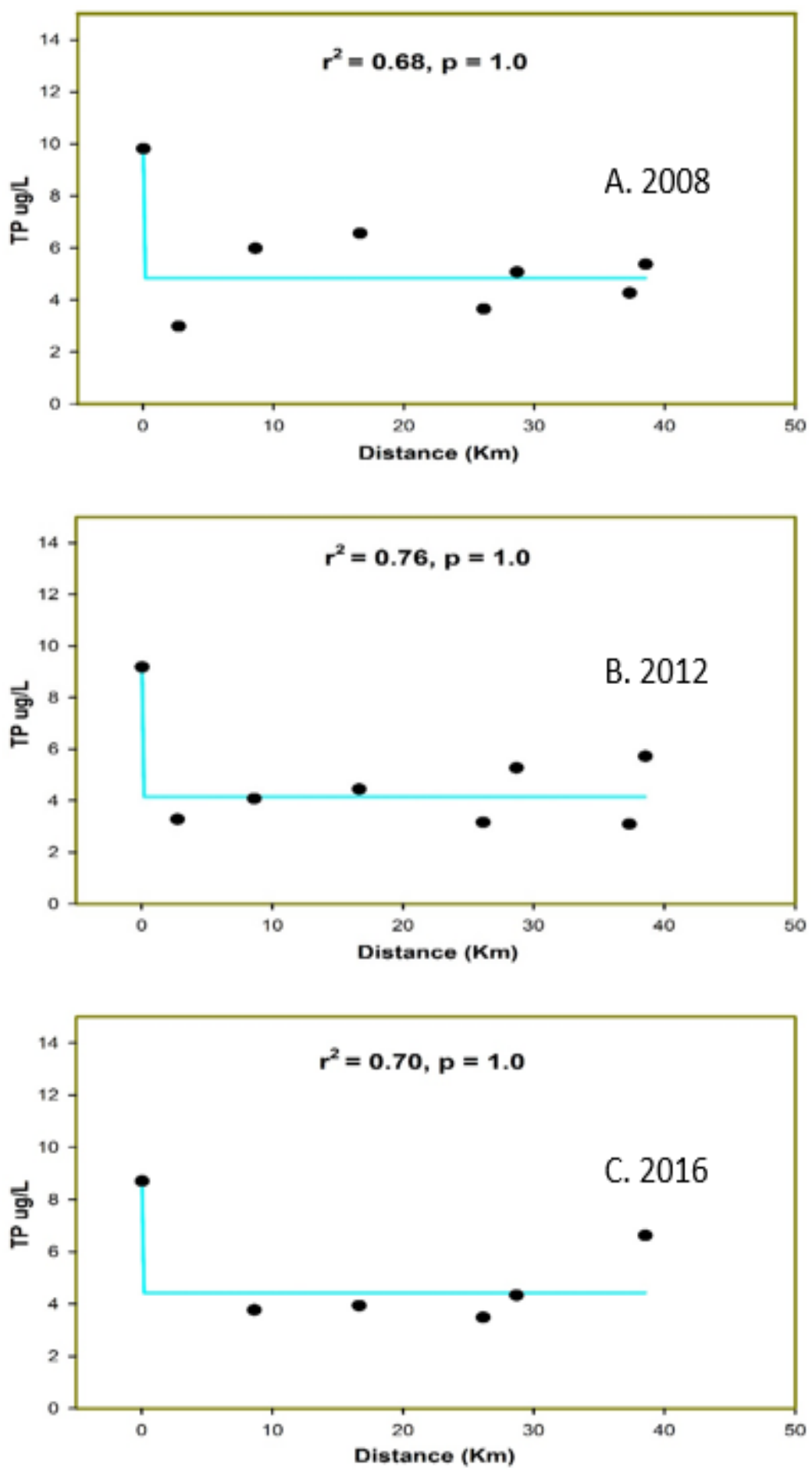

Figure 9: Trend of total phosphorus in surface water from 2008 to 2016 at ENP transect. (A, B, C) represents comparison of model fit among years at transect 5 . The curve didn't fit in any of the years $(p=1.0)$ 


\subsection{Soil TP distribution analysis}

Both increasing and decreasing trends of soil TP concentration were observed across the EPA from 2004 to 2014 (Figure 10). The empirical cumulative distribution function (CDF) found that the probability of high soil TP were tend to increase in $2014(524 \pm 282 \mu \mathrm{g} / \mathrm{g})$ than $2004(503 \pm 254 \mu \mathrm{g} / \mathrm{g})$ (Figure 11). The skewness of soil TP data was also higher in $2014(1.96 \pm 0.2 \mu \mathrm{g} / \mathrm{g})$ than in $2004(1.51 \pm 0.07 \mu \mathrm{g} / \mathrm{g})$. However, the nonparametric Wilcoxon Rank Sum test showed no statistical significance difference $(p=0.205)$ soil TP among the year from 2004 to 2014 across the EPA (Figure 11). Though there were no significant changes found in overall EPA data from 2004 to 2014 but significant mixed trends were found in individual hydrologic units (i.e. WCAs and ENP) that as explained below.

By analyzing GIS unique value distribution results we found that in 2004, among 954 sample points, $22.11 \%$ of them had soil TP greater than $500 \mu \mathrm{g} / \mathrm{g}$ which were considered as "impacted soils" defined by 62-302.540 F.A.C (Figure 12) (Qian et al. 2004). Among 237 sample points in 2005 , about $25 \%$ exceeded the soil TP range of $500 \mu \mathrm{g} / \mathrm{g}$ while about $20.4 \%$ point had soil TP in between 400 to $500 \mu \mathrm{g} / \mathrm{g}$ (Figure 13). Only a few number (62) of data points were sampled in 2013 any only from within WCA3 and ENP. Among 62 points, approximately $16.12 \%$ stations exceeded the soil TP limit of $500 \mu \mathrm{g} / \mathrm{g}$ where about $17.74 \%$ sites had TP concentrations between 400 to $500 \mu \mathrm{g} / \mathrm{g}$ (Figure 14) in 2013. Among 131 sample points, about $24 \%$ sites were considered as impacted (> $500 \mu \mathrm{g} / \mathrm{g}$ ) in 2014 across the EPA which was slightly higher than the previous years (Figure 15). 


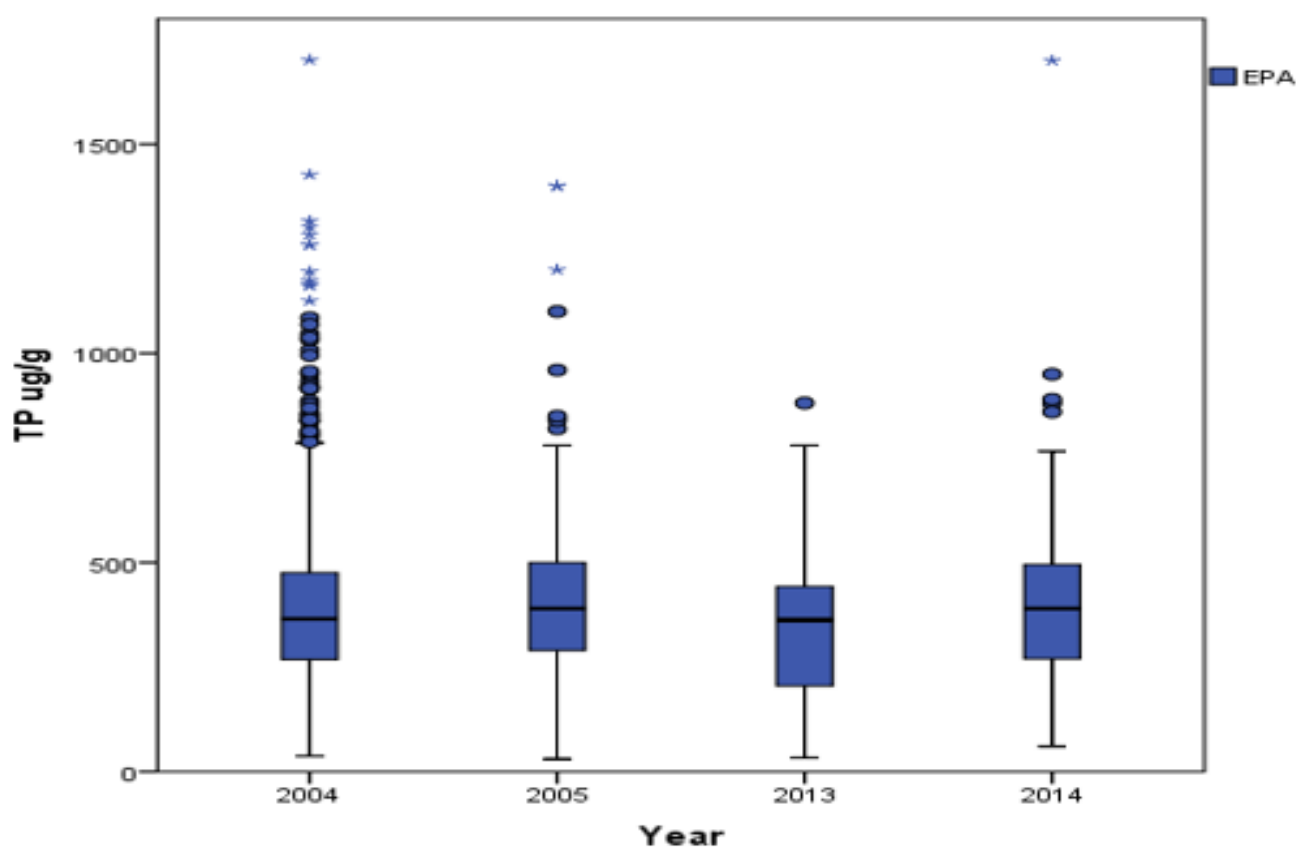

Figure 10: The distribution of TP concentrations in EPA soil from 2004 to 2014.

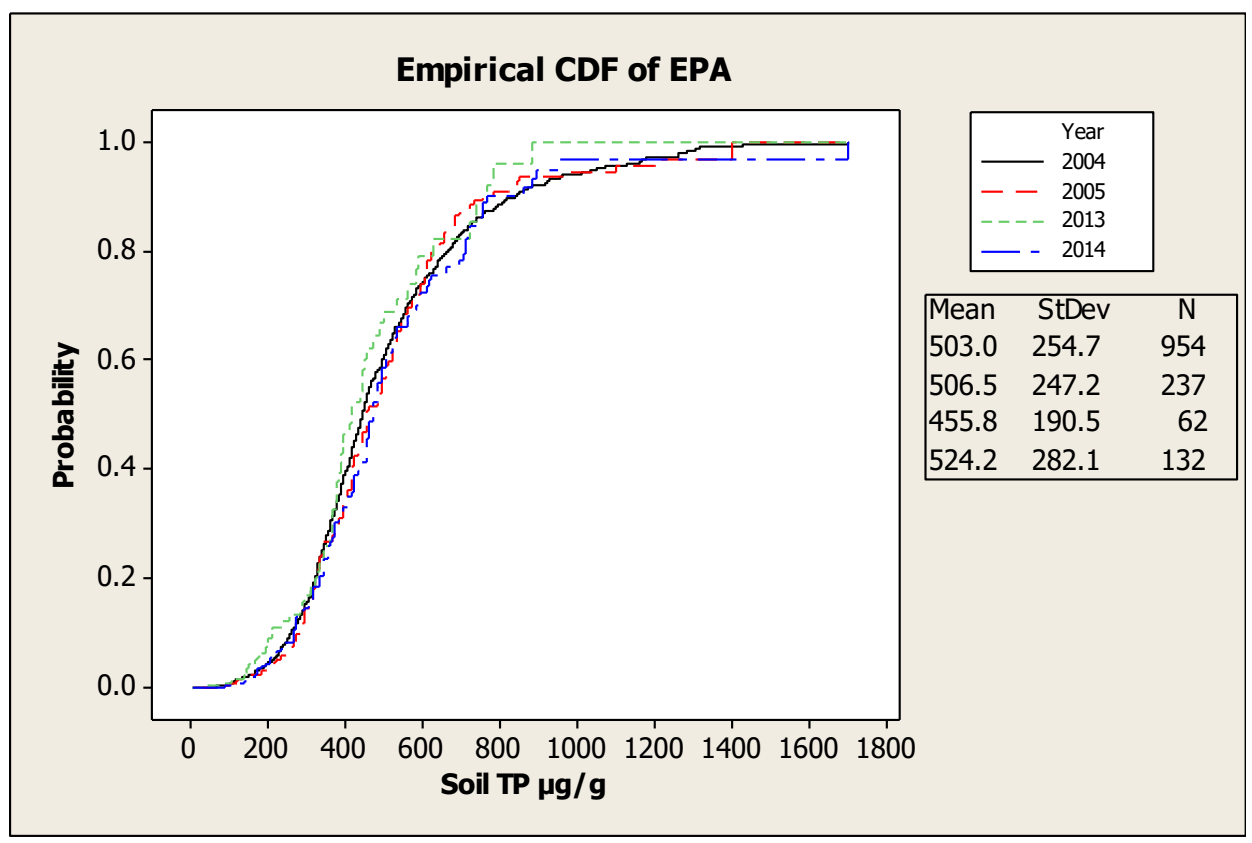

Figure 11: The empirical CDF curve showed the probability function of soil TP observed in 2004 to 2014. Independent Kruskal-Wallis test found no significant difference at $95 \%$ Confidence Interval $(p=0.205)$ among the study year. 


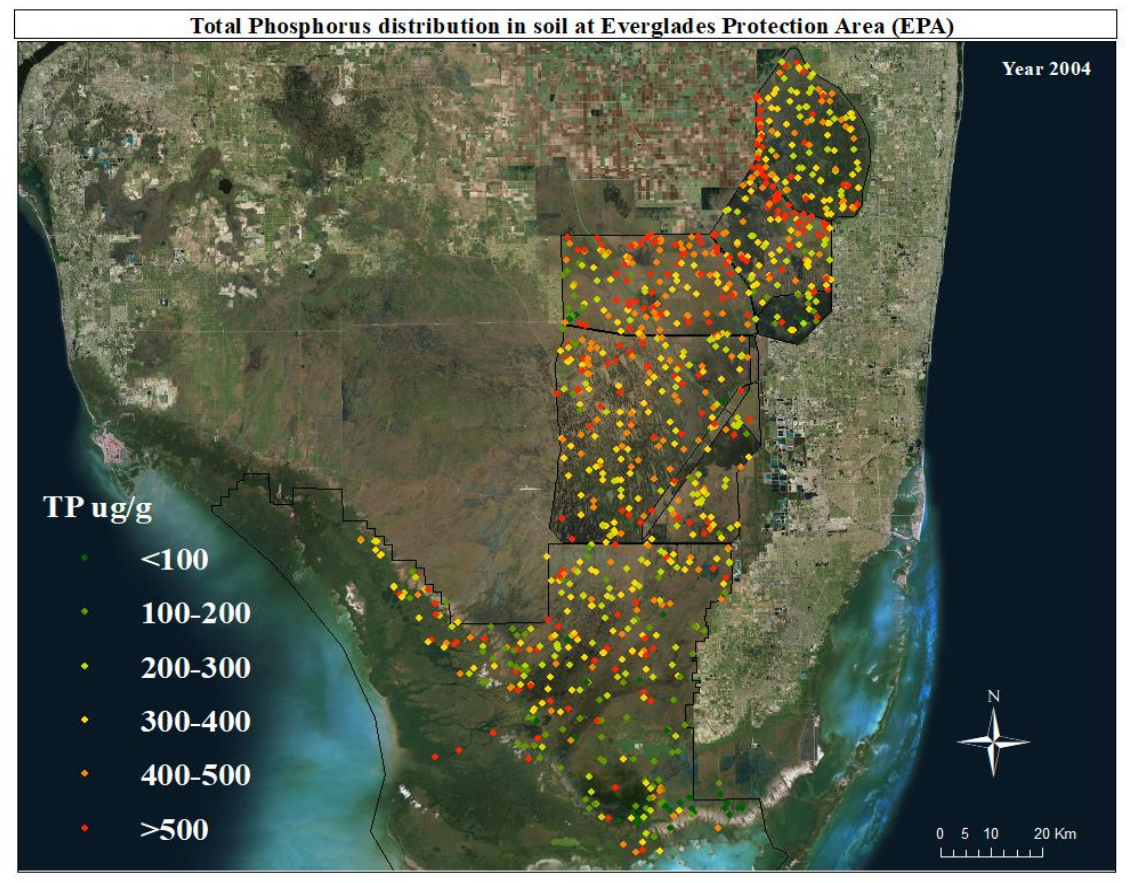

Figure 12: Concentration of soil TP in 2004 across the EPA (Color shows the ranges of $\mathrm{TP}$ in $\mu \mathrm{g} / \mathrm{g}$ dry weight soil)

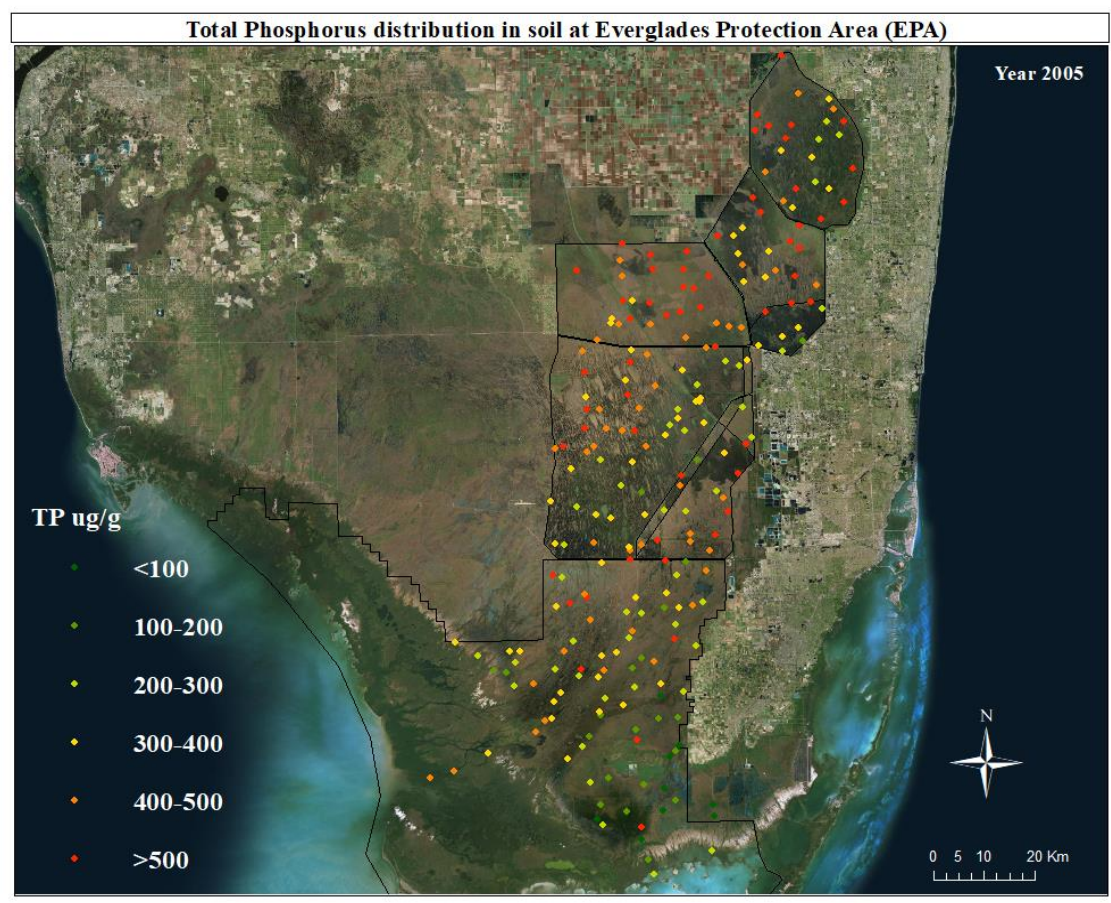

Figure 13: Concentration of soil TP in 2005 across the EPA (Color shows the ranges of TP $\mu \mathrm{g} / \mathrm{g}$ in dry weight soil) 


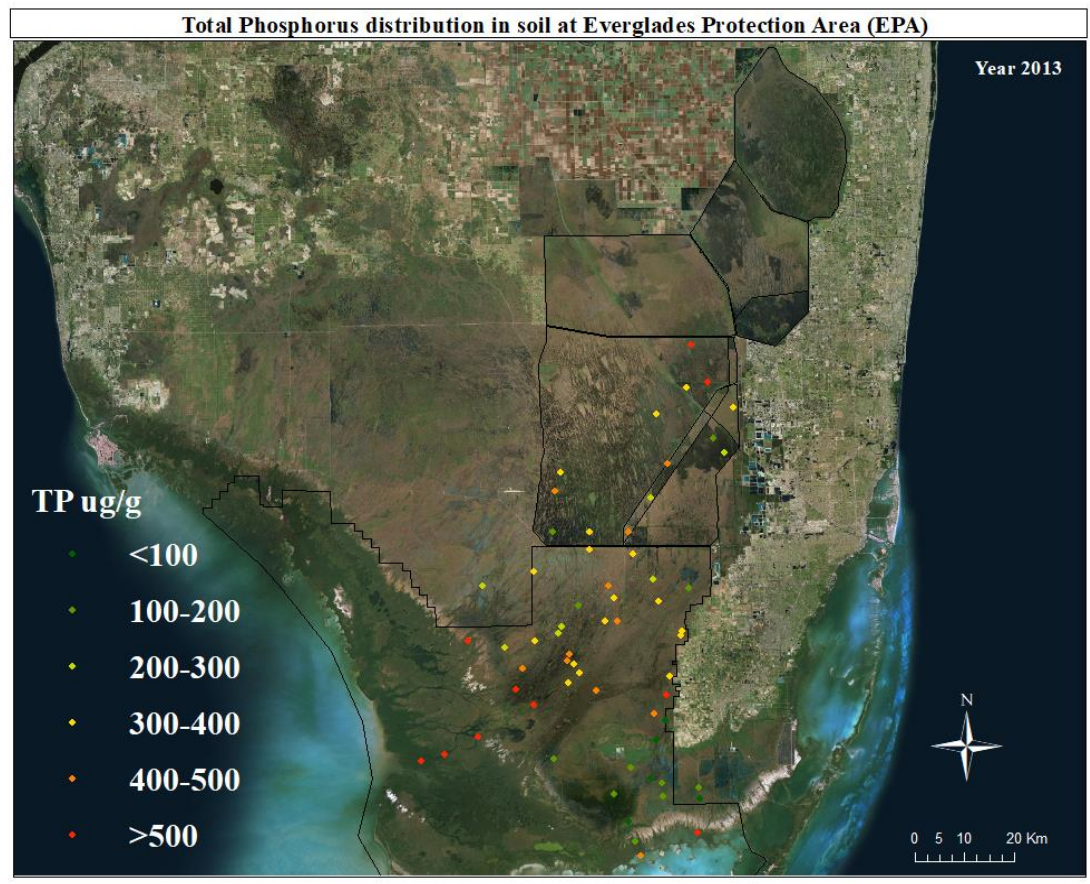

Figure 14: Concentration of soil TP in 2013 across the EPA (Color shows the ranges of $\mathrm{TP} \mu \mathrm{g} / \mathrm{g}$ in dry weight soil)

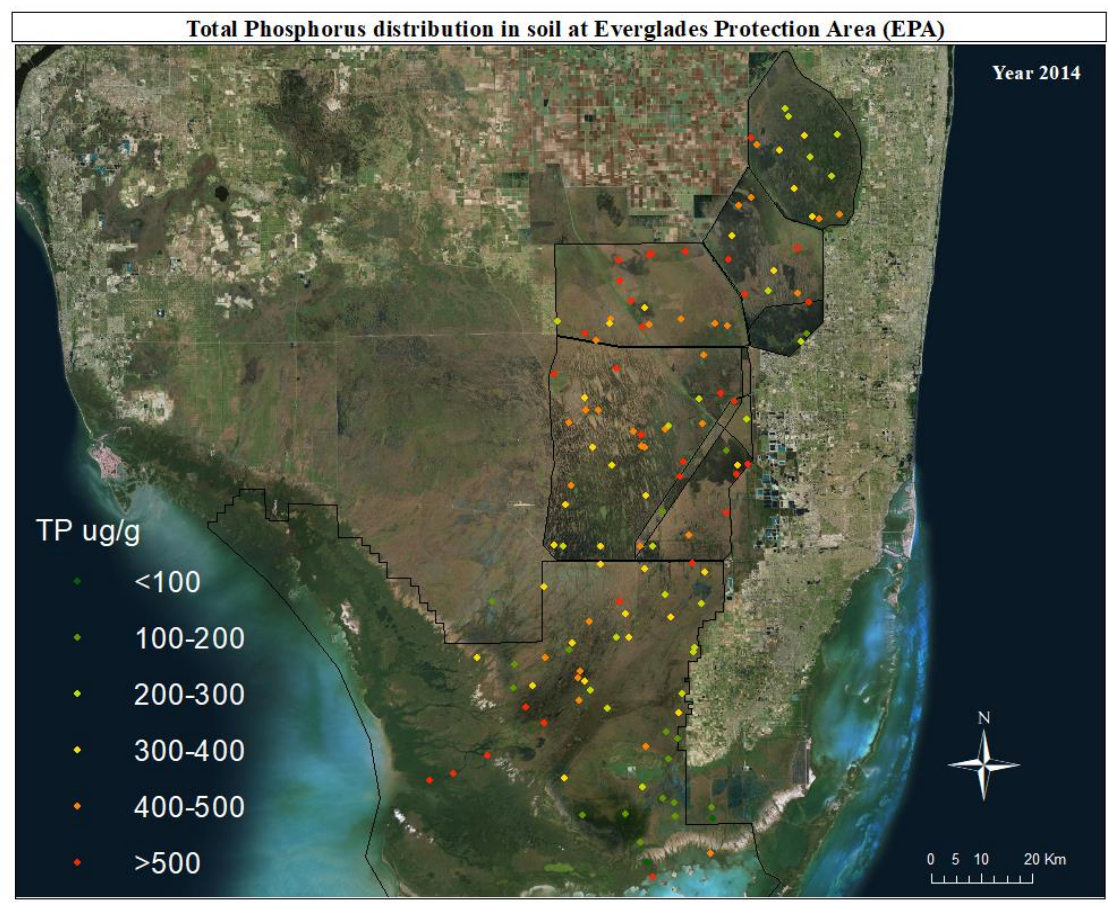

Figure 15: Concentration of soil TP in 2014 across the EPA (Color shows the ranges of $\mathrm{TP} \mu \mathrm{g} / \mathrm{g}$ in dry weight soil) 
The GIS proximity analysis showed that the higher TP concentrations ( $>500 \mu \mathrm{g} / \mathrm{g}$ ) tended to occur within a distance of less than $10 \mathrm{~km}$ from the canal boundaries across the EPA throughout the years. Though the proximity result for soil TP were coherent for WCAs but in ENP where higher TP ( $>500 \mu \mathrm{g} / \mathrm{g}$ ) concentrations were also found in areas about $50 \mathrm{~km}$ from the discharge point throughout the study period (Figure 16).

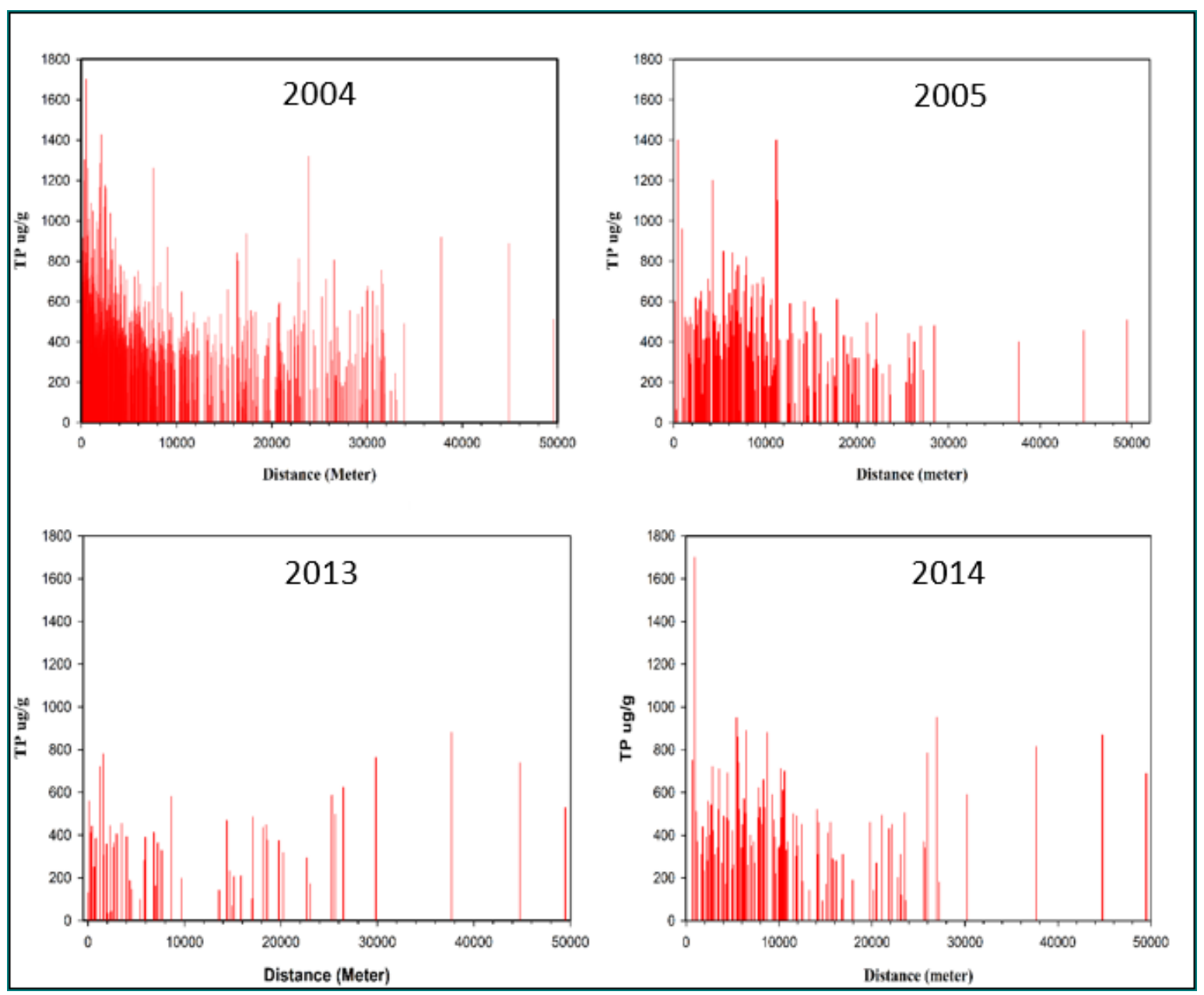

Figure 16: Distribution of soil TP concentrations with distance from the inflow canal boundaries throughout the period 2004 to 2014 across the EPA 


\subsubsection{Soil TP distribution in WCA1}

In WCA1, soil TP was found to decrease significantly from 2004 to 2014. The nonparametric Wilcoxon Rank Sum test showed that the mean $(404 \pm 13 \mu \mathrm{g} / \mathrm{g}) \mathrm{TP}$ concentration in 2004 had significantly decreased $(381.3 \pm 35.9 \mu \mathrm{g} / \mathrm{g})$ in 2014 at the $95 \%$ confidence interval $(\mathrm{p}=0.047)$ (Figure 17). The skewness of soil TP data in $2014(1.8 \pm$ $0.6 \mu \mathrm{g} / \mathrm{g})$ was higher than in $2004(1.5 \pm 0.2 \mu \mathrm{g} / \mathrm{g})$. The highest TP concentrations (>1000 $\mu \mathrm{g} / \mathrm{g}$ ) of soil TP were identified in the northwestern site of WCA1 at distances less than 1 $\mathrm{km}$ from the discharge points throughout the year from 2004 to 2014 (Figure 16).

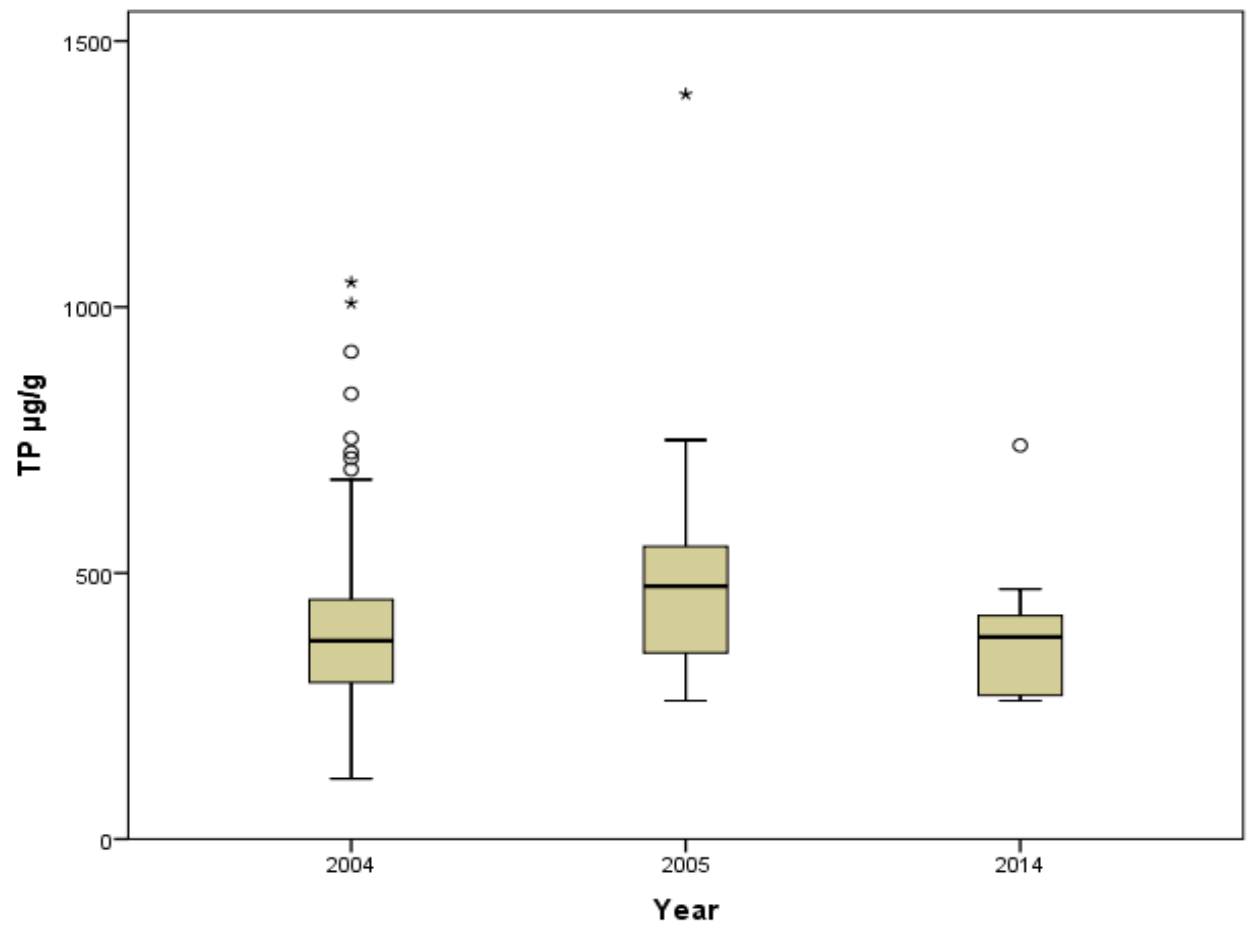

Figure 17: Distribution of soil TP in WCA1 from 2004 to 2014. Independent sample Kruskal-Wallis test determined the significant difference of soil TP among the study years at $95 \%$ confidence interval $(\mathrm{p}=0.042)$. 


\subsubsection{Soil TP distribution in WCA2}

A declining trend in mean soil TP was observed in WCA2 from $2004(512 \pm 27 \mu \mathrm{g} / \mathrm{g})$ to $2014(465 \pm 61 \mu \mathrm{g} / \mathrm{g})$ while the median soil TP increased from $2004(396 \mu \mathrm{g} / \mathrm{g})$ to 2014 (460 $\mu \mathrm{g} / \mathrm{g})$. According to a Wilcoxon Rank Sum test, there was no significant difference in either the mean and median soil TP among the years from 2004 to 2014 (Figure 18). The GIS proximity analysis showed that the highest soil TP (530 to $1200 \mu \mathrm{g} / \mathrm{g}$ ) was prevalent within WCA2 within $5 \mathrm{~km}$ from the discharge points (Figure 16).

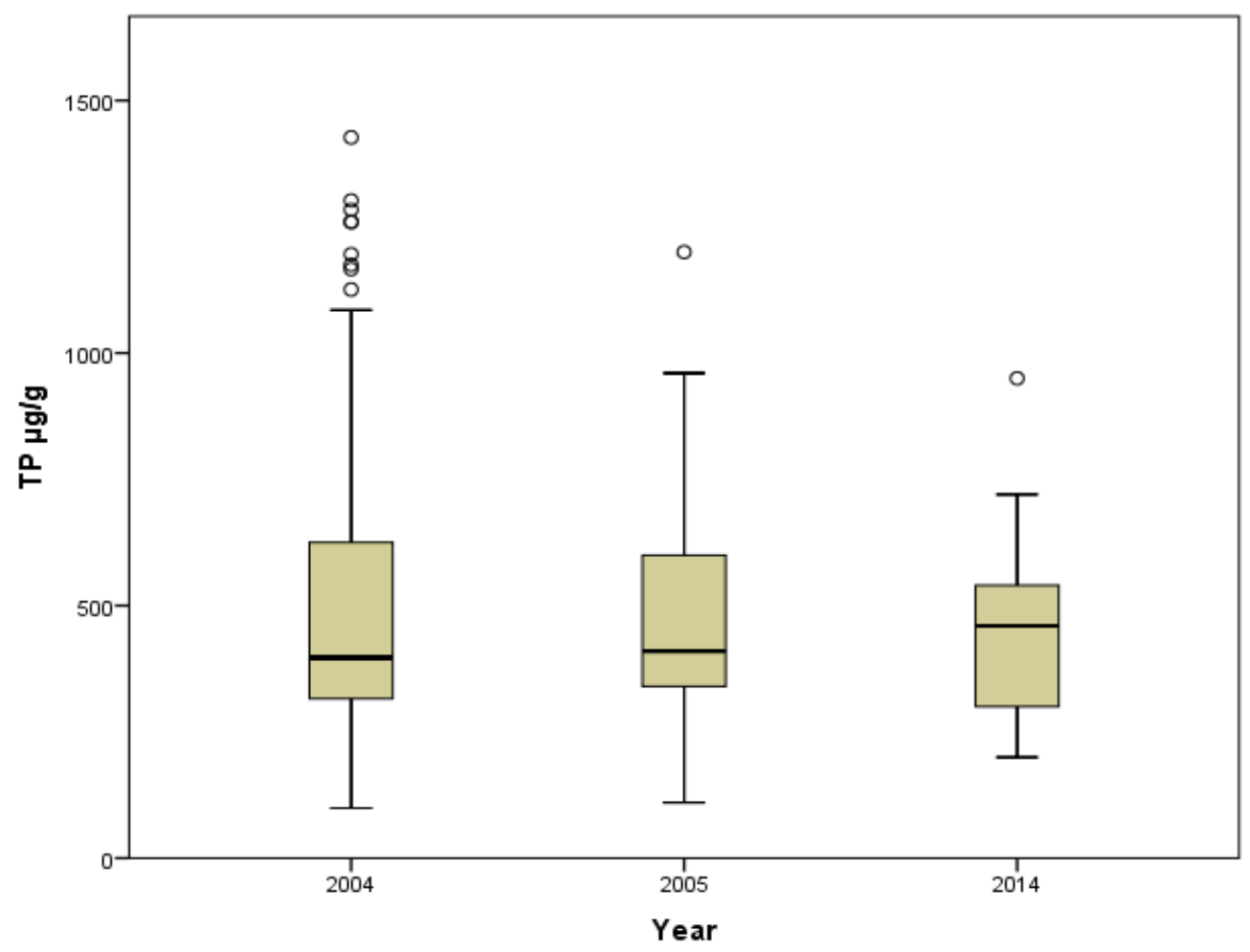

Figure 18: Distribution of soil TP in WCA2 from 2004 to 2014. Independent sample Kruskal-Wallis test didn't find the significant difference of soil TP among the study years at $95 \%$ confidence interval $(\mathrm{p}=0.944)$ 


\subsubsection{Soil TP distribution in WCA3}

The mean TP concentrations in soil in WCA3 increased from $2004(416 \pm 8 \mu \mathrm{g} / \mathrm{g})$ to 2014 $(489 \pm 32 \mu \mathrm{g} / \mathrm{g})$. As observed in the other hydrologic units, the data skewness in 2014 $(2.6 \pm .3 \mu \mathrm{g} / \mathrm{g})$ was higher than $2004(1 \pm 0.1 \mu \mathrm{g} / \mathrm{g})$ in WCA3. The non-parametric Wilcoxon Rank Sum test determined the significant difference throughout the year at the $95 \%$ confidence interval $(\mathrm{p}=0.017)$ (Figure 19). The highest concentration of soil TP $(1700 \mu \mathrm{g} / \mathrm{g})$ was recorded in WCA 3B at the distance about 800 meter from the L-30 canal boundaries (Figure 16).

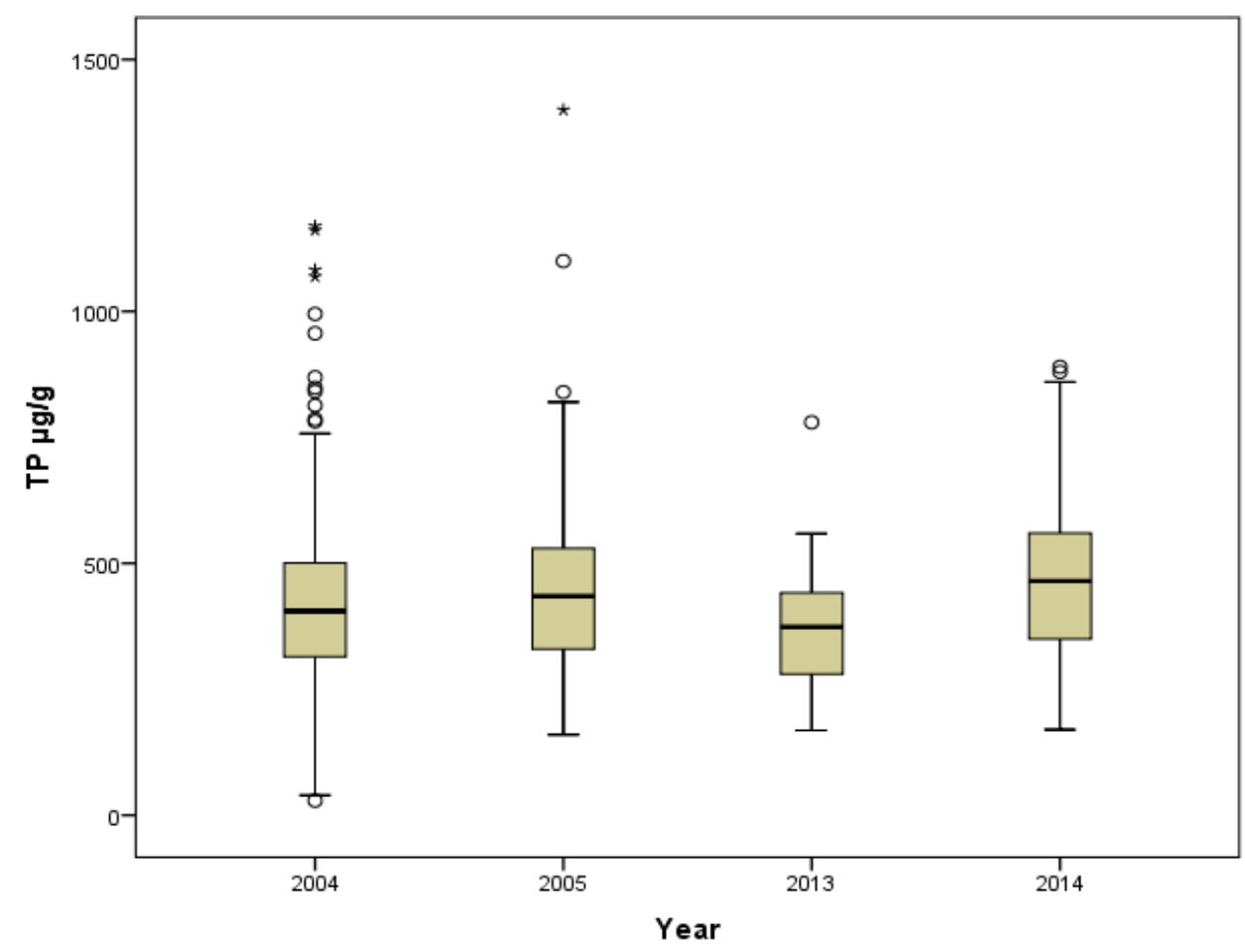

Figure 19: Distribution of soil TP in WCA3 from 2004 to 2014. Independent sample Kruskal-Wallis test determined the significant difference of soil TP among the study years at $95 \%$ confidence interval $(\mathrm{p}=0.017)$ 


\subsubsection{Soil TP distribution in ENP}

In ENP, the mean soil TP in $2014(332 \pm 23 \mu \mathrm{g} / \mathrm{g})$ was higher than in $2004(317 \pm 10 \mu \mathrm{g} / \mathrm{g})$, but the non-parametric Wilcoxon Rank Sum test didn't find any significant difference among the study years (Figure 20).

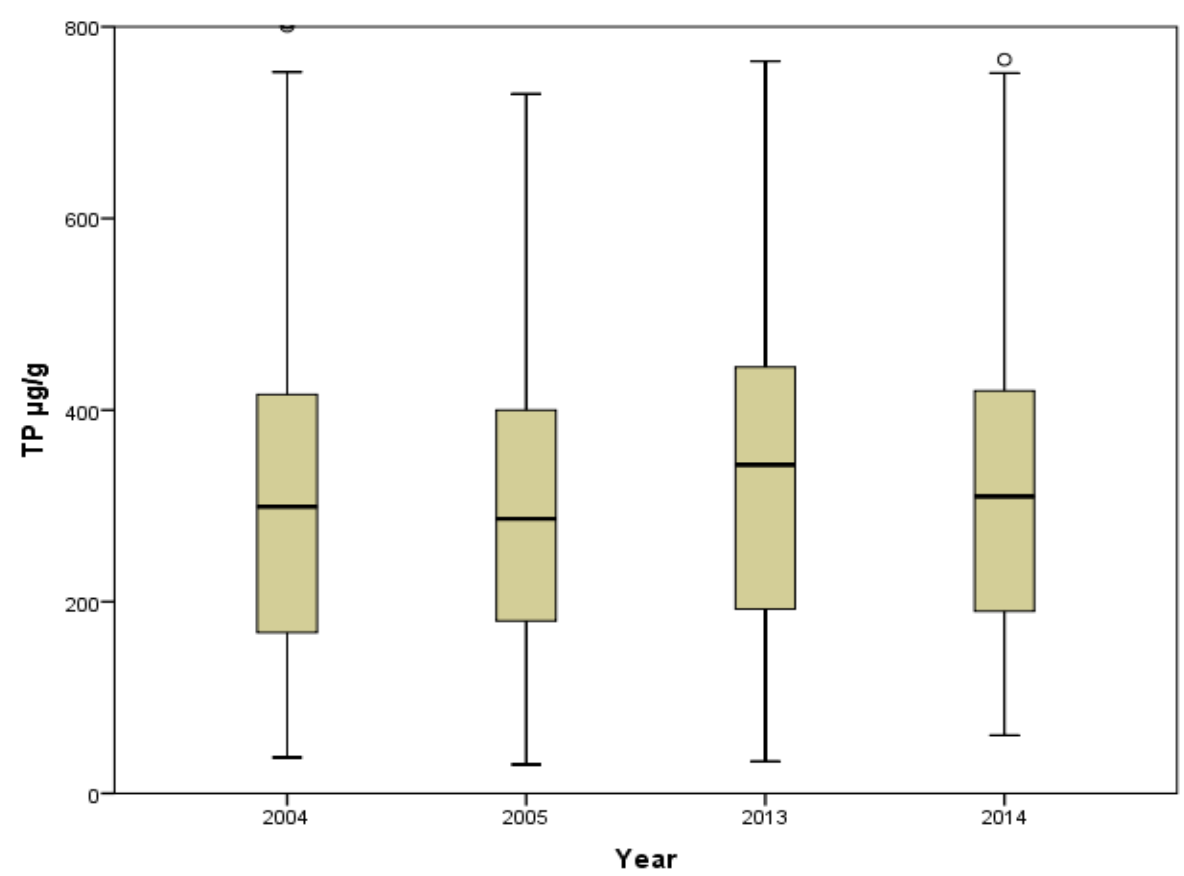

Figure 20: Distribution of soil TP in ENP from 2004 to 2014. Independent sample Kruskal-Wallis test didn't find any significant difference of soil TP among the study year at $95 \%$ confidence interval $(\mathrm{p}=0.580)$

However, there was a significant difference observed in TP between the different soil types occurring within ENP. In peat soil, the mean TP concentration $(374.33 \pm 19.22 \mu \mathrm{g} / \mathrm{g})$ was higher than in marl soil $(274.68 \pm 17.34 \mu \mathrm{g} / \mathrm{g})$ from 2005 to 2014 using data from the ENP REMAP sites (Figure 21). 


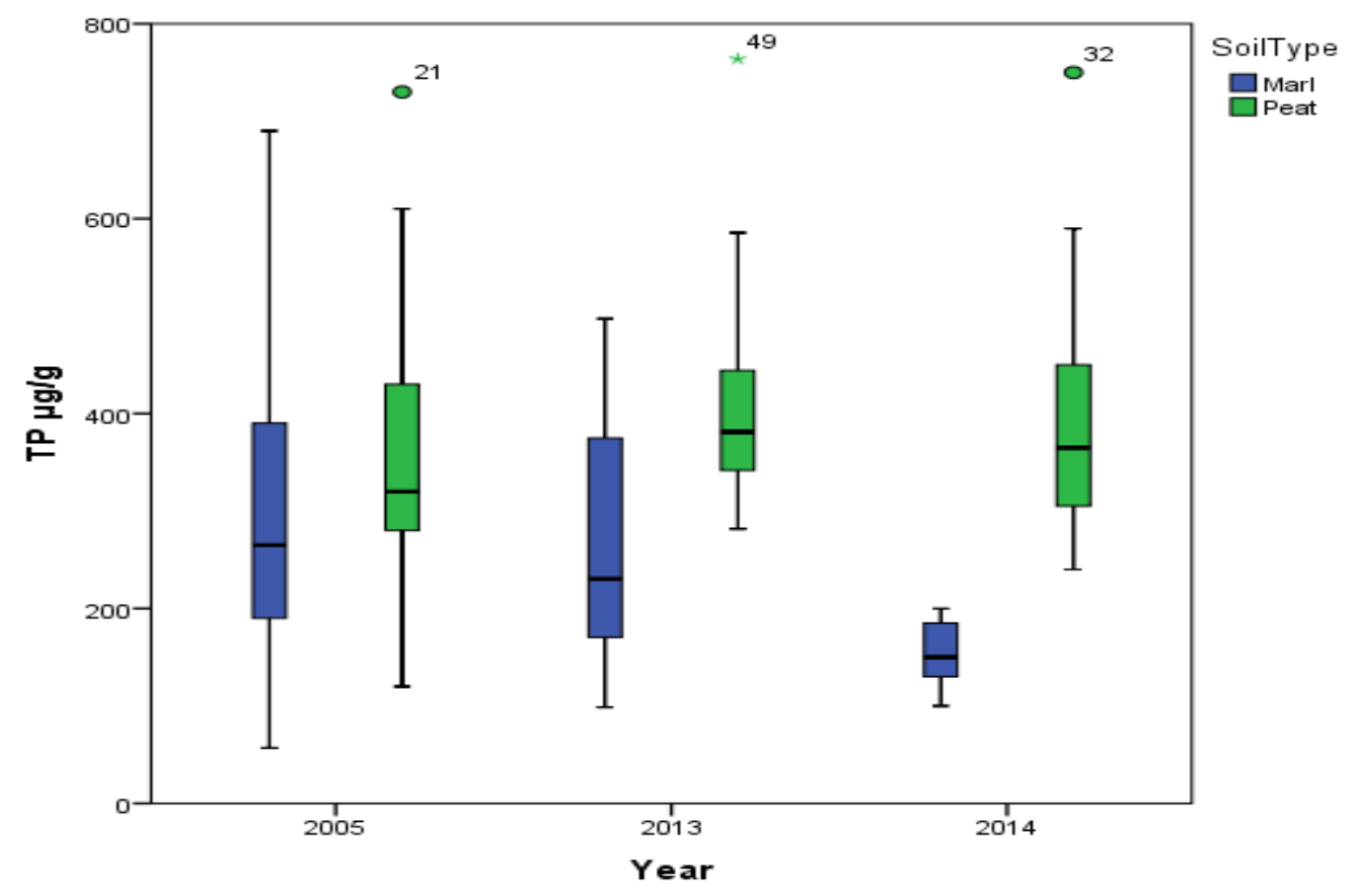

Figure 21: Distribution of TP concentration in peat and marl soil at ENP throughout the year from 2004 to 2014. Independent sample Mann-Whitney test determined the significant of soil TP among the study years at $95 \%$ confidence interval $(\mathrm{p}=$ $0.03)$

Though the concentration of soil TP was higher in peat than marl, we found the opposite results in mass soil TP per unit area between these soil types. In marl soil, there was a significant increase in soil TP per unit area than peat soil throughout the study year in the ENP (Table 3).

\begin{tabular}{|r|l|r|r|r|}
\hline \multicolumn{1}{|l|}{ Year } & Soil Type & Mean TP $\mu \mathrm{g} / \mathrm{g}$ & Mean BD g/cm3 & Mean TP g/m2 \\
\hline $\mathbf{2 0 0 5}$ & Marl & 297.30 & 0.34 & 8.82 \\
\hline $\mathbf{2 0 0 5}$ & Peat & 342.67 & 0.27 & 7.73 \\
\hline $\mathbf{2 0 1 3}$ & Marl & 275.69 & 0.45 & 11.75 \\
\hline $\mathbf{2 0 1 3}$ & Peat & 400.67 & 0.18 & 6.18 \\
\hline $\mathbf{2 0 1 4}$ & Marl & 242.00 & 0.34 & 7.76 \\
\hline $\mathbf{2 0 1 4}$ & Peat & 387.89 & 0.19 & 6.59 \\
\hline
\end{tabular}

Table 3: Volumetric basis of mean soil TP per unit area in marl soil and peat soil in the ENP. BD=Bulk Density. 


\subsection{Seasonality analysis of surface water TP}

The annual GM averaged TP in surface water was significantly higher in the wet season $(16.8 \pm 0.7 \mu \mathrm{g} / \mathrm{L})$ than the dry season $(13.9 \pm 0.5 \mu \mathrm{g} / \mathrm{L})$ from 2004 to 2016 across the EPA. Although a declining trend in the GM averaged TP was found in both seasons, the results were still higher than the threshold limit (>10 $\mu \mathrm{g} / \mathrm{L}$ ) throughout the study period (Figure 23). The non-parametric Wilcoxon rank sum test determined a significant difference between wet and dry season at $95 \%$ confidence interval through the year from 2004 to 2016 (Figure 22). The Seasonal variability in the surface water TP was also observed across all hydrologic units (i.e. WCAs, ENP) from 2004 to 2016.

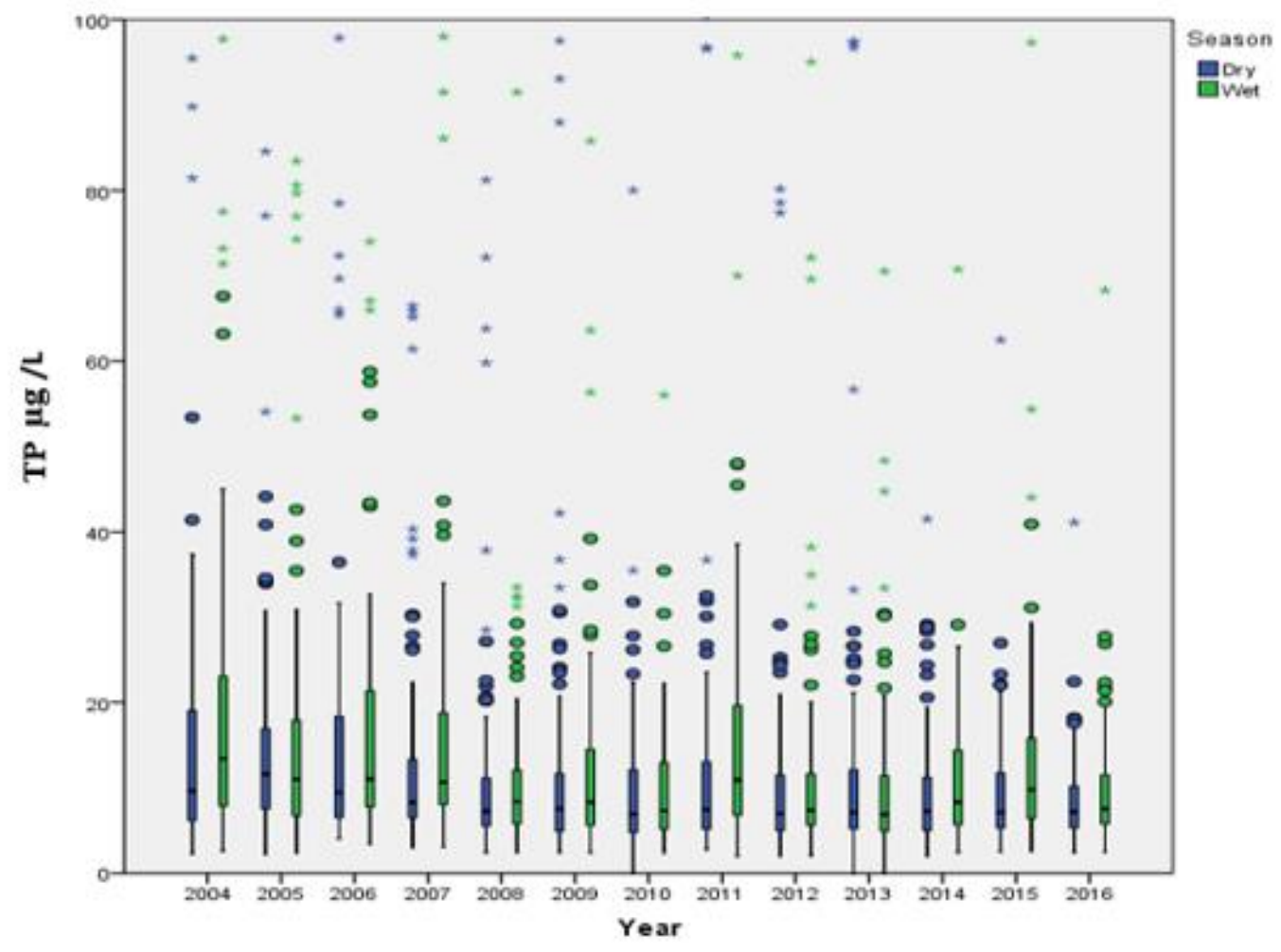

Figure 22: Annual GM TP concentrations in surface water in dry and wet season across the EPA from 2004 to 2016. Independent sample Mann-Whitney test determined the significant difference between the seasons at $95 \%$ confidence interval 


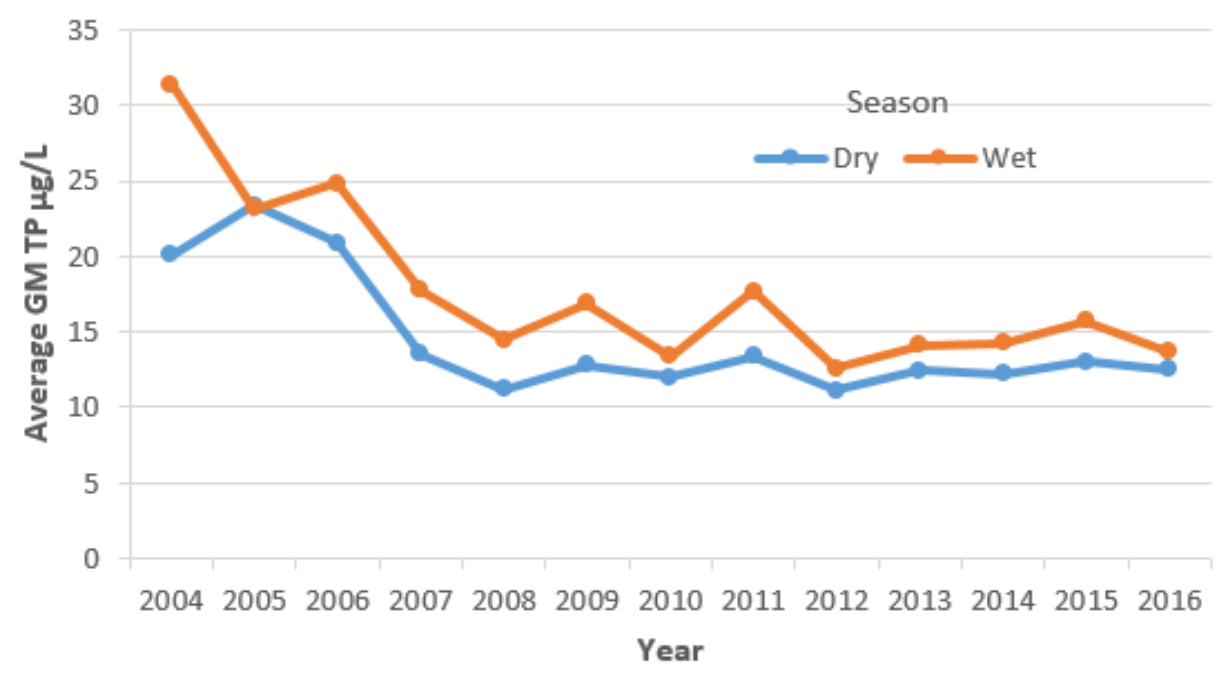

Figure 23: Seasonal GM averaged TP in the EPA from 2004 to 2016

\subsubsection{Seasonal Trend of TP concentration in WCA1}

Though the average annual GM TP concentrations in water decreased in WCA1 from 2004 to 2016, there was a substantial significant difference observed between dry and wet seasons. Among all hydrologic units, the highest TP concentrations in surface water were found in WCA1 where the annual GM TP in the dry season was recorded between $3.9 \mu \mathrm{g} / \mathrm{L}$ to $192.7 \mu \mathrm{g} / \mathrm{L}$. The TP concentrations in the wet season varied between $5.3 \mu \mathrm{g} / \mathrm{L}$ to 200.3 $\mu \mathrm{g} / \mathrm{L}$ (Figure 24) throughout the study year. Moreover, in both dry and wet seasons, the annual GM averaged TP in 2016 was still higher than $10 \mu \mathrm{g} / \mathrm{L}$ across the all sites in the WCA1 which exceeded the class III water quality criterion. However the median GM TP concentration for all stations was still below $10 \mu \mathrm{g} / \mathrm{L}$ meaning that there were some sites closer to the discharge points (Figure 4) with higher TP concentrations resulting this difference across all stations in WCA1. The nonparametric Wilcoxon Rank sum test 
showed the significance difference between seasons for the years 2004 to 2016 across the EPA (Figure 24).

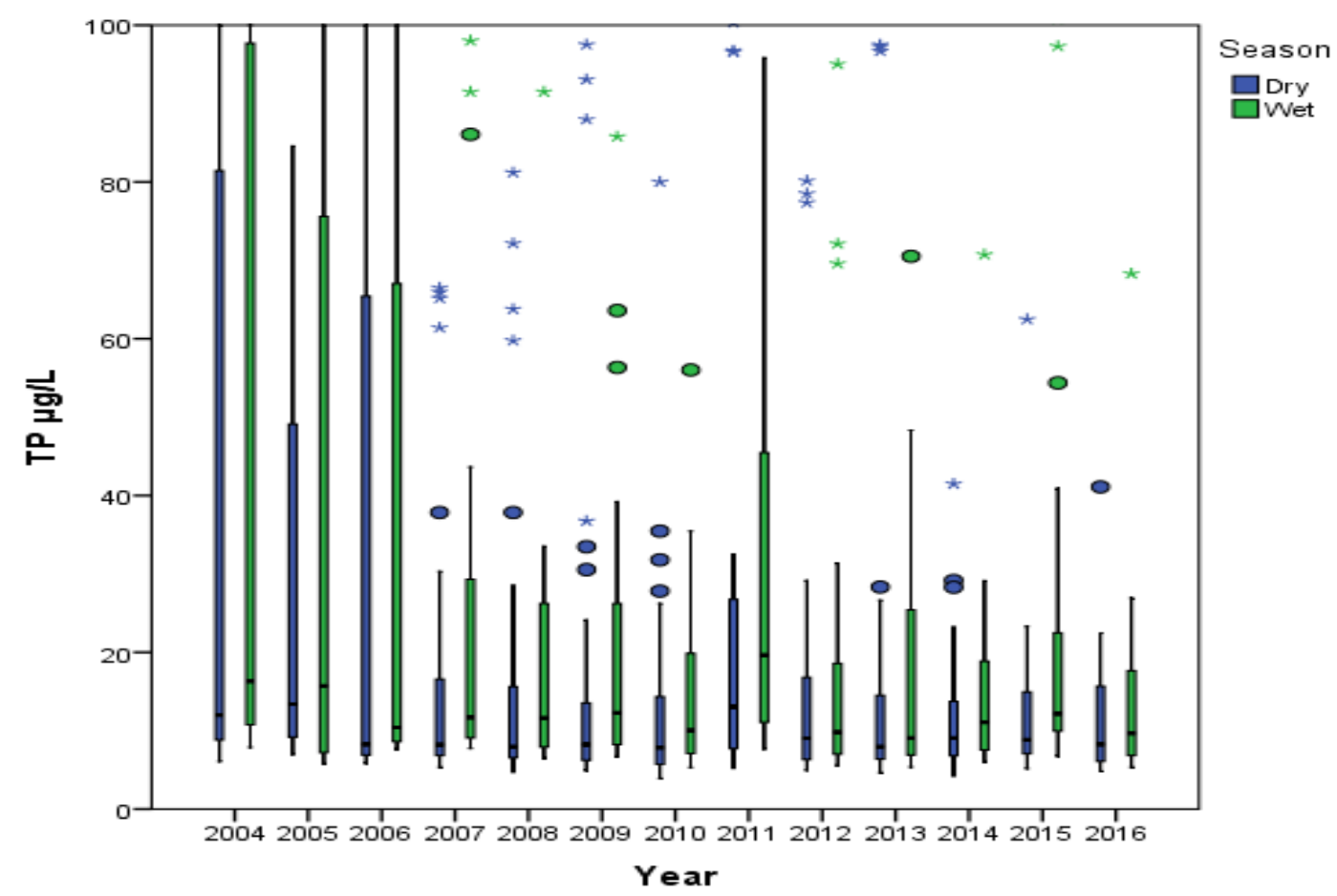

Figure 24: Seasonal variability of annual GM TP in the WCA1 from 2004-2016. Independent Kruskal-Wallis test found the significant difference between wet and dry season throughout the study year at $95 \%$ confidence interval $(p=0.000)$

\subsubsection{Seasonal Trend of TP concentration in WCA2}

In WCA2, though the average annual GM averaged TP decreased from $2004(24.6 \pm 4.43$ $\mu \mathrm{g} / \mathrm{L})$ to $2016(10 \pm 0.66) \mu \mathrm{g} / \mathrm{L}$, there were still 14 stations out of 34 with an annual GM TP greater than $10 \mu \mathrm{g} / \mathrm{L}$ (Appendix 1). There were no significant difference found in the water TP between the dry and wet seasons throughout the study year at $95 \%$ confidence interval (Figure 25). 


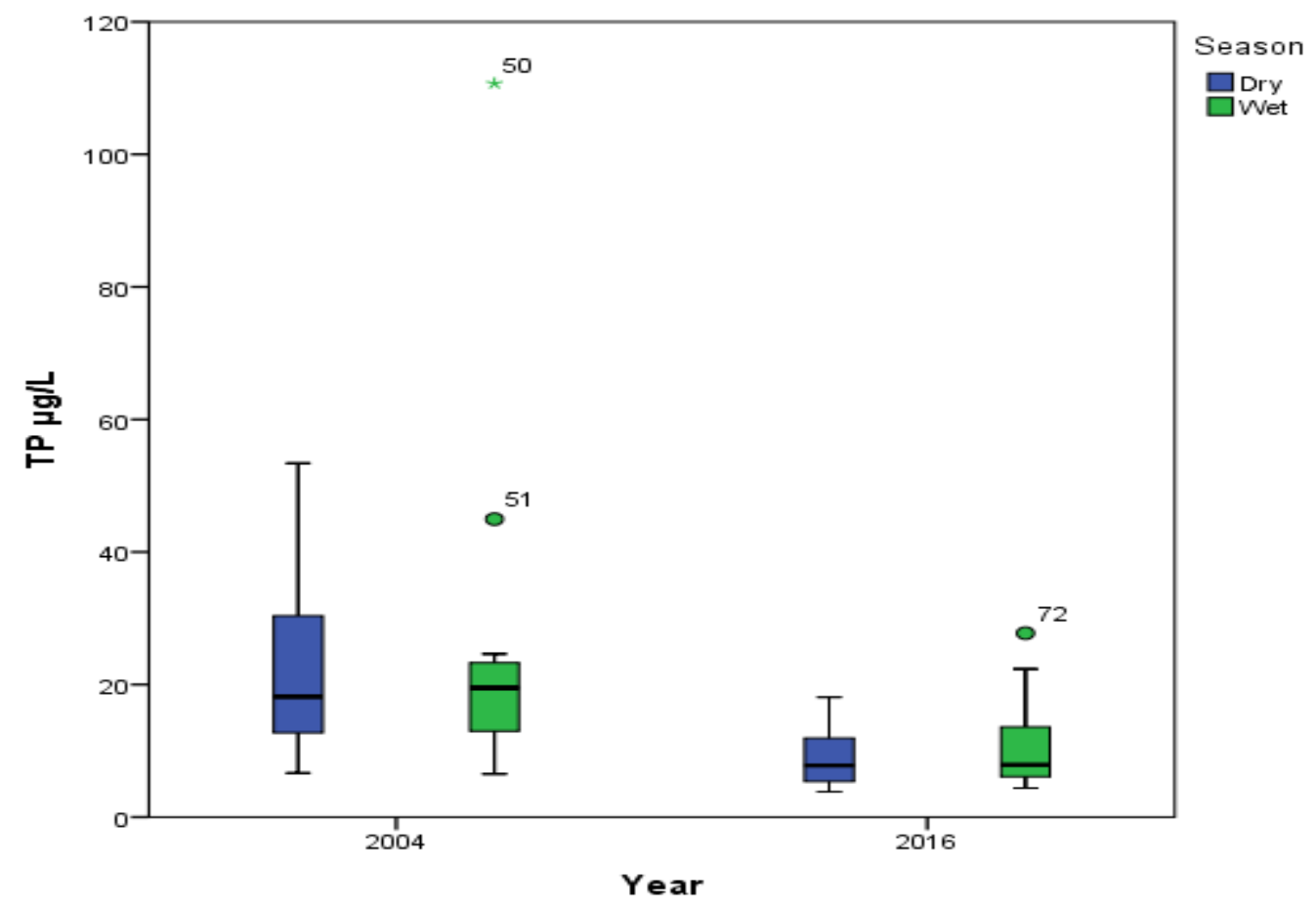

Figure 25: Comparison of annual GM TP for dry and wet season at WCA2 from 2004 to 2016. Independent sample Mann-Whitney test didn't result any significant difference of water TP in dry and wet season throughout the year at $95 \%$ confidence interval $(\mathrm{p}=0.532)$

\subsubsection{Seasonal Trend of TP concentration in WCA3}

In WCA3, there was a substantial decline found in surface water TP from 2004 to 2016 in both seasons. The annual GM TP concentrations dropped from $77 \mu \mathrm{g} / \mathrm{L}$ to $16 \mu \mathrm{g} / \mathrm{L}$ from 2004 to 2016 (Figure 26). There were only 11 stations out of 35 which had TP concentrations greater than $10 \mu \mathrm{g} / \mathrm{L}$ in both dry and wet seasons (Appendix 1). However, there were also four more sites along the Tamiami Trail which had TP greater than $10 \mu \mathrm{g} / \mathrm{L}$ in the wet seasons. The annual GM averaged TP across the WCA3 were less than $10 \mu \mathrm{g} / \mathrm{L}$ in last five years except in the 2015 wet season (Appendix 1). There was a significant difference observed between dry and wet seasons throughout the years from 2004 to 2016 at the $95 \%$ confidence interval (Figure 26). 


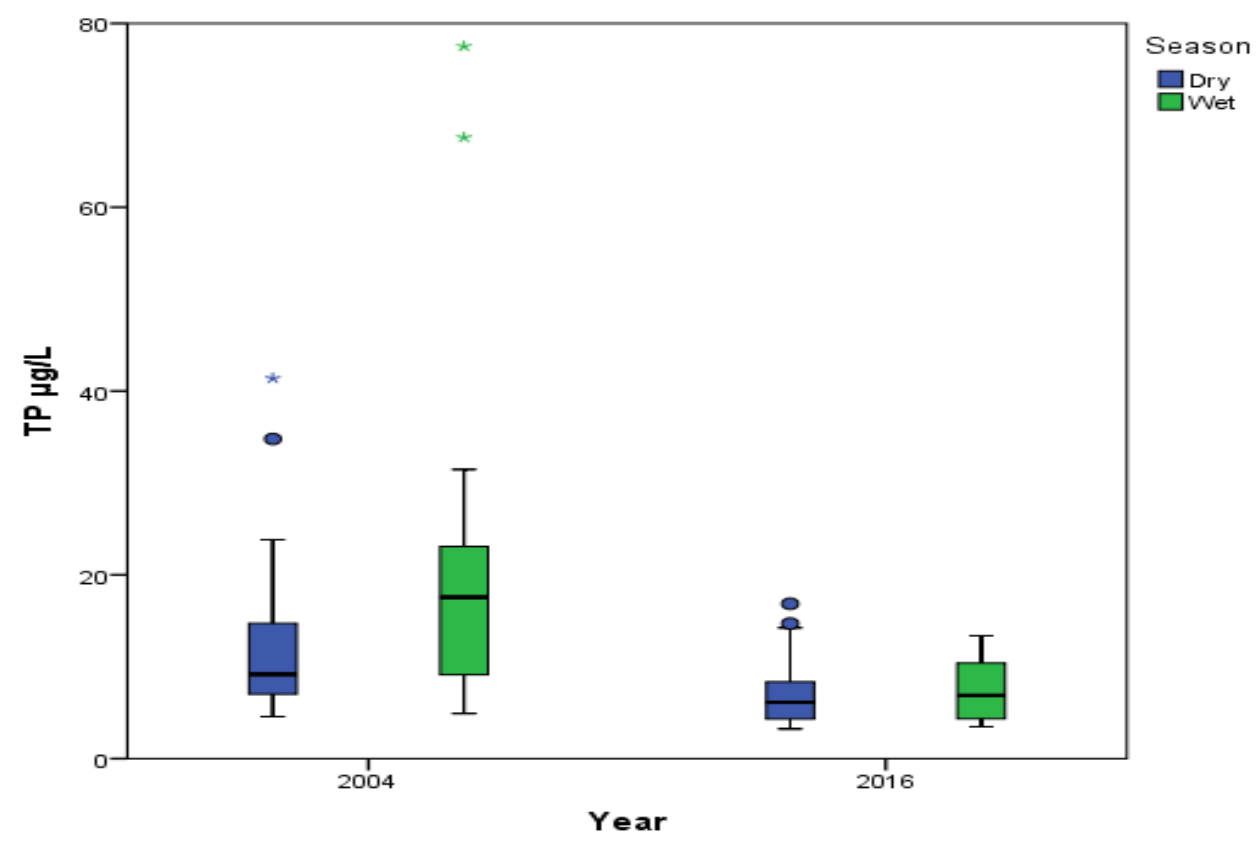

Figure 26: Comparison of annual GM TP for dry and wet seasons at WCA3 from 2004 and 2016. Independent sample Mann-Whitney test didn't find any significant difference in water TP between the dry and wet seasons at the $95 \%$ confidence interval $(\mathrm{p}=0.061)$.

\subsubsection{Seasonal Trend of TP concentration in ENP}

In ENP, a significant decline of TP concentrations was observed throughout the study years. The annual GM TP decreased from $17.5 \mu \mathrm{g} / \mathrm{L}$ to $12.9 \mu \mathrm{g} / \mathrm{L}$ in 2004 to 2016 . Furthermore, there were no sites in the dry season which had TP concentrations greater than $10 \mu \mathrm{g} / \mathrm{L}$ in 2016 (Figure 27). Only four canal sites near the Tamiami canal had higher TP>10 $\mu \mathrm{g} / \mathrm{L}$ in the 2016 wet season (Appendix 1). The annual GM averaged TP concentrations met class III water quality criterion throughout the study period. The nonparametric Mann-Whitney test didn't result in any significant difference between dry and wet season TP throughout the year from 2004 to 2016 at the $95 \%$ confidence interval (Figure 27). 


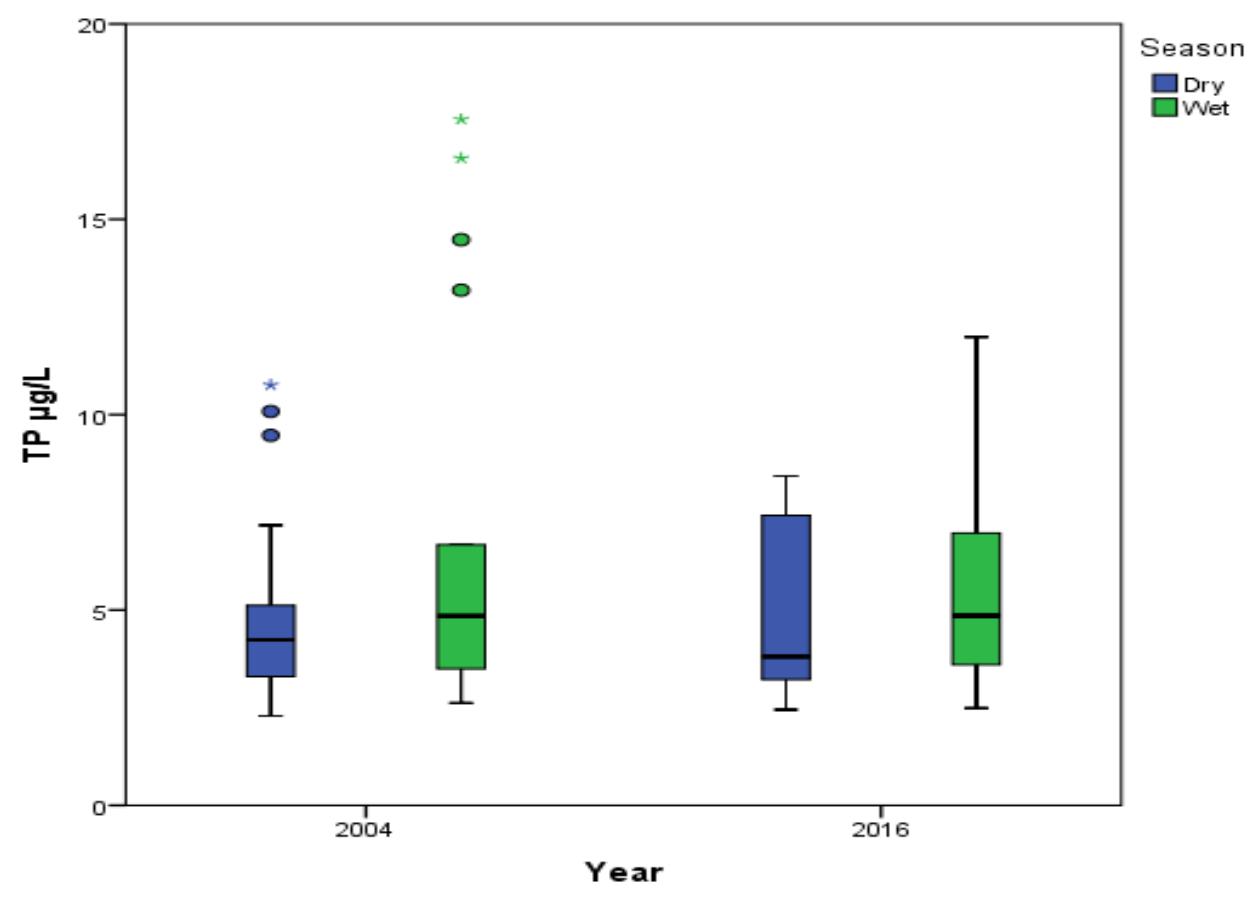

Figure 27: Comparison of annual GM TP for dry and wet season at ENP from 2004 to 2016. Independent sample Mann-Whitney test didn't find any significant difference of water TP in dry and wet season throughout the year at $95 \%$ confidence interval $(\mathrm{p}=0.109)$ 


\section{DISCUSSION}

In general the concentration of TP in surface water in the EPA declined in the last two decades most likely due to the implementation of CERP including STAs and BMPs (Davidson et al 2017). Generally 95 percent of the TP load in surface water comes from EAA basin to EPA via the STAs (Davidson et al. 2017). According to Davidson et al. (2017) about 70 percent of the TP load has been reduced in the EAA basin within the last two decades due to the implementation of the STAs and BMPs. Despite the long-term decline in surface water TP concentrations observed across the EPA, high concentrations of TP in surface water $(10 \mu \mathrm{g} / \mathrm{L})$ were still observed in 2016 at or near discharge points in all hydrologic basins compared to down gradient marsh areas. The elevated TP observed at the discharge points would still be expected to cause an ecosystem imbalance potentially changing the natural vegetation communities (Gaiser et al. 2006).

The lowest TP concentration in surface water was observed in ENP as it is the southernmost region of EPA and receives comparatively cleaner water than the WCAs. According to Surrett et al. (2014), the northeastern canal boundaries (close to urban edge) of ENP, particularly the L67A and L-29 canals, are major sources of elevated TP to the ENP. This study found the highest surface water TP concentrations (above $10 \mu \mathrm{g} / \mathrm{L}$ ) in ENP to be less than $1 \mathrm{~km}$ of the Tamiami canal which feeds into the L67A and L-29 canals, thereby supporting the findings of Surrett et al. (2014).

Our results indicated that surface water within ENP had already achieved the class III water quality criterion in last few years but there was a significant impact of TP in soil. The majority of the downstream marsh sites in ENP had TP concentrations in surface water less 
than ecological threshold with no spatial gradient resulting in a lack of significant model fit. Others have found that the variability of $\mathrm{P}$ distribution and fractionation in canal and marsh sediments in Everglades occurred primarily due to the difference in physiochemical properties (e.g. soil organic matter, bulk densities etc.), biological environments (e.g. flora, fauna, microorganisms etc.), and hydrologic conditions (e.g. water flows, depth etc.) (Wang et al. 2011), which are interconnected to response of TP changes in water at EPA. The exponential decay model used in this investigation was first developed for Everglades soils (Childers et al. 2003), but worked well in describing TP concentrations in surface water for a majority of transects except in ENP. In WCA2, there was no significant decrease found in water TP in first four kilometers from the canal boundaries supported the finding by (Childers et al. 2003) observed in Everglades soil. Childers et al. (2003) mentioned that the soil $\mathrm{P}$ retention capacity was saturated within $4 \mathrm{~km}$ of the canal resulting no substantial decrease in TP within this area. However, from the $4 \mathrm{~km}$ site, there was a significant exponential decline found in water TP towards the interior of WCA2. The upstream water management scheme and regional hydrology could have impacted this TP variability in WCA2.

Like surface water, TP in Everglades soil has a substantial impact in ecosystem change across the EPA. In general, nutrient enrichment and altered hydrology has an impact on soil biogeochemical process which act as driving forces of changing environmental quality, subsequently degrades the Everglades ecosystem (Koch and Reddy 1992; Davis 1994; Noe et al. 2001). Also wetland soils act as an integrator of long-term environmental conditions (e.g. water quality, hydrology etc.) and serve as important tools to access environmental changes (DeBusk et al. 1994; Scheidt and Kella 2007). We analyzed the TP concentrations 
from 2004 to 2014 where both increasing and decreasing trends were identified in soil TP across the EPA. As the physiography of Everglades is spatially different from north to south, there were mixed trend found in individual hydrologic units throughout this period. Our findings indicated that the soil TP across the EPA varied throughout the year but, in general increased from 2004 to 2014. The variability in the TP through the years may be attributable due to differences in sampling frequencies, for instance there were only 62 sites sampled in 2013 whereas 954,237, 132 sites were sampled in respectively 2004, 2005, and 2014. Also the higher outlier of soil TP present in 2004 and higher skewness in 2014 than other years might have influenced this variability.

The significant decreasing trend in soil TP of WCA1 from 2004 to 2014 found in this investigation support the previous results of Corstanje et al. (2006), who also reported a decrease of impacted sites in WCA1 from 1995 to 2004. Among all the WCAs, the WCA1 is unique as it is dome shaped and raised relative in the surrounding canals (Swift and Nicolas 1987) and the water inputs to WCA1 from water pump and canals. The substantial decrease in WCA1 was possibly due to the ongoing restoration implemented mostly in upstream basin of WCA1 (e.g. STA, BMP),

The smallest unit in the EPA is WCA 2 which receives nutrient influx from upstream canals located in agricultural areas. The higher mean soil TP found in 2014 than in previous years implied a higher TP accumulation in recent years. In WCA2, the mean soil TP concentrations in 2014 were higher than the threshold limit (> $450 \mu \mathrm{g} / \mathrm{g}$ ) beyond which the TP enrichment alter the structural pattern (i.e. cattail incursions) of its vegetation communities (DeBusk et al. 2001). The cattail expands at those sites less than $5 \mathrm{~km}$ from 
the discharge points though its connection of TP enrichment depends on other factors such as hydrology, climate, and fire (Davis 1994). Also fire could be one of the drivers to change the TP storage in the soil due to process such as resuspension of floc and translocation of soil TP in both horizontal and vertical direction (Davis 1994).

Moreover, there were significant increases in soil TP found in WCA3 from 2004 to 2014. Unlike WCA1, there were an increasing trend determined in WCA3 where the majority of the soils were Histosols which mainly developed in deep surface layer with high organic matter. The significant increase of mean TP from 2004 to 2014 in WCA3 supports the previous spatio-temporal analysis of soil TP within this area conducted by Bruland et al. (2006). The most impacted zone of WCA3 is the northern part of WCA3A, possibly due to nutrient inputs from the Miami canal. The eastern site of WCA3B was impacted which might associate with nutrient inputs from both L67A and L-28 canals. Moreover, continued soil oxidation due to subsidence and fire have impact on TP enrichment at these sites resulted the internal loading of $\mathrm{P}$ (Osborne et al. 2011). Both Bruland et al. (2006) and Scheidt and Kella (2007) documented the significant soil loss in northern WCA3A and eastern part of WCA3B in previous their studies which also supports these findings.

Our findings from both soil and water, indicated that the highest TP concentrations in surface water and soil were prevalent at or below the distance in $1 \mathrm{~km}$ from discharge points throughout the EPA. However, we identified the higher soil TP concentrations greater than $500 \mu \mathrm{g} / \mathrm{g}$ at the distance about $50 \mathrm{~km}$ downstream from the canal boundaries at coastal Shark River Slough (SRS) FCE LTER sites close to Florida Bay which possibly influenced by marine environment (Osborne et al. 2011) as well as extreme weather events such as 
hurricane or drought during the study period. The ENP is comparatively least impacted unit of EPA in term of TP enrichment. Commonly peat soils tend to have higher TP concentrations than marl soil due to high amount of organic content present in peat. However, in volumetric basis, the marl soils appeared to be higher TP in per unit area than the peat soils because of higher bulk density and lower organic matter. The Osborne et al. (2011) mentioned that the oxidation rate of Everglades soil is much higher than the accretion rate thus soil oxidation could have affected for TP enrichment in WCA3A and ENP in 2014 than previous decade. As P enrichment is prevalent in these areas, continued losing of peat soil has potential to increase the trends that could result the cattail expansion (Osborne et al. 2011).

Water management strategies (human intervention), seasonality, and amount of rainfall (natural intervention) on the marsh and upstream areas are the principal factors affecting wetland hydrology and ultimately the role of TP alteration in a wetland system. (Smith et al. 2001). Since the inception of CERP, significant efforts were made to control the TP loading within the EAA basin, and this study confirmed a reduction in surface water TP across the EPA from 2004 to 2016. However, when investigated on a seasonal basis, a significant increasing trend in the surface water TP concentrations was observed in the wet season across the EPA contradicting results published by Zapata et al. (2012). Generally, the surface water flow in the wet season has higher TP concentrations than dry season because of resuspension during the rewetting of the system (Surratt et al. 2014). The higher surface water TP identified along the Tamiami canal (Boundary of ENP) in the wet season which possibly by the effect of dividing the WCA3 into two individual impoundments. Atmospheric factors (i.e. hurricane, rainfall, and drought) may also play a role in the 
observed seasonal differences as both wet and dry deposition is a major nutrient source to the Everglades (Reddy et al. 2005).

\section{CONCLUSION}

Understanding the dynamics of TP in Everglades soil and surface water is necessary in order to monitor the effectiveness of CERP, the largest environmental restoration initiatives approved in 2000 by US Congress. Findings from this study indicate a significant decrease in surface water TP concentrations in EPA transects from 2008 to 2016. Despite the decrease, GM averaged TP concentrations observed in individual hydrologic units were still higher than the threshold limit of water quality criterion. The spatial-temporal analysis didn't indicate a significant increase in soil TP from 2004 to 2014 across the EPA except in WCA3. In almost all instances, the highest TP concentrations in both water and soil were found within a $1 \mathrm{~km}$ distance from discharge points or canals. Higher TP concentrations were also observed in ENP FCELTER sites close to the Florida Bay. The seasonal GM TP concentration in surface water was higher in the wet season than the dry season across the EPA throughout the period from 2004 to 2016. Other studies combining TP in water and soil with climate, hydrology, soil type, and vegetation communities are critical to elucidate the TP enrichment throughout the system. Furthermore, TP loads depend on water flow, and combining studies of TP concentrations with flow (Flow weighted mean) will provide a better explanation of TP accumulation throughout the system. As the restoration efforts are ongoing, the continuous monitoring efforts are vital in order to take management decisions that will balance human needs abreast of maintaining healthy ecosystem functioning. 


\section{REFERENCES}

Bruland, G.L., Grunwald, S., Osborne, T. Z., Reddy, K. R., and Newman, S. (2006). Spatial distribution of soil properties in Water Conservation Area 3 of the Everglades. Soil Sci. Soc. Am J., 70, 1662-1676

Chen, H., Ivanoff, D., Pietro, K. (2015). Long-term phosphorus removal in the Everglades stormwater treatment areas of South Florida in the United States. Ecological Engineering (79). 158-168

Childers, D.L., Doren, R. F., Jones, R., Noe, G.B., Rugge, M., Scinto, L.J. (2003). Decadal Changes in Vegetation and soil Phosphorus Pattern across the Everglades Landscape. J Environ Qual 32: 344-362

Childers, D.L., Gaiser, E.E., Ogden. L. (2016). The Coastal Everglades: The Dynamics of Social-Ecological Transformation in the South Florida Landscape. Oxford University Press. Submitted

Corstanje, R., Grunwald, S., Reddy, K. R., Osborne, T. Z., \& Newman, S. (2006). Assessment of the spatial distribution of soil properties in a Northern Everglades marsh. Journal of Environmental Quality, 35, 938-949.

Das, J., Daroub, S.H., Bhadha, J.H. et al. ((2012). Phosphorus Release and Equilibrium Dynamics of Canal Sediments within the Everglades Agricultural Area, Florida, Water Air Soil Pollutant 223: 2865-2879.

Davis, S.M., Ogden, J.C. (1994). Everglades: The Ecosystem and its restoration. St. Lucie Press. Delray Beach, p 826.

Davis, S. M. (1994). Phosphorus inputs and vegetation sensitivity in the Everglades. In: S. M. Davis, \& J. C. Ogden (Eds.), Everglades: The ecosystem and its restoration (p. 826). Delray Beach: St. Lucy Press.

DeBusk,W.F., Reddy, K.R., Koch, M.S., and Wang, Y. (1994). Spatial patterns of soil Phosphorus in Everglades water conservation area 2A. Soil Sci. Soc. Am. J., 58, 543-552.

Doren, R.F., Armentano, T. V., Whiteaker, L.D., and Jones, R.D. (1996). Marsh vegetation Patterns and soil phosphorus gradients in the Everglades ecosystem. Aquatic Botany, 56, $145-163$.

Gaiser, E.E., Trexler, J. C., Richards, J.H., Childers, D.L., Lee, D., Edwards, A. L., Scinto, L.J., Jayachandran, K., Noe, G.B. and Jones, R.D. (2005). Cascading Ecological Effects of Low-Level Phosphorus Enrichment in the Florida Everglades 
Julian II, P. (2016). Commentary on "Mitsch et. al., 2015. Protecting the Florida Everglades wetlands: Can stormwater phosphorus be reduced to oligotrophic conditions?" Ecological Engineering.

Gaiser, E. E., D. L. Childers, R. D. Jones, J. H. Richards, L. J. Scinto, and J. C. Trexler (2006), Periphyton responses to eutrophication in the Florida Everglades: Cross-system patterns of structural and compositional change, Limnol. Oceanogr. 51: 617-630,

Harvey, R.G., Loftus, W. F., Rehage, J. S., and Mazzotti, F.J. (2014). Effcts of Canals and Levees on Everglades Ecosystems: Circular, Wildlife Ecology and Conservation Department, UF/IFAS Extension. http://edis.ifas.ufl.edu/uw349

Julian P, Payne GG, Xue SK (2015) Water quality in the Everglades Protection Area. In: 2016 South Florida Environmental Report. South Florida Water Management District, West Palm Beach, Florida, p 55

Light, S. S., \& Dineen, J. W. (1994). Water control in the Everglades: a historical perspective. Everglades: The ecosystem and its restoration. 5: 47-84.

Naja, M., Childers, D.L., and Gaiser, E.E. (2017), Water quality implications of hydrologic restoration alternatives in the Florida Everglades, United States

Newman, S., K.R. Reddy, W.F. DeBusk, and Y. Wang. (1997). Spatial distribution of soil nutrients in a northern Everglades marsh: Water Conservation Area 1. Soil Sci. Soc. Am. J. 61:1275-1283.

Noe, G.B., Childers, D. L., and Jones, R. D. (2001). Phosphorus biogeochemistry and the impact of phosphorus enrichment: Why is the Everglades so unique? Ecosystems. 4: 603624.

Osborne,Todd Z. , Newman, Susan, Scheidt, Daniel J. , Kalla, Peter I. , Bruland, Gregory L. Cohen, Matthew J., Scinto, Leonard J. and Ellis, Larry R. (2011) 'Landscape Patterns of Significant Soil Nutrients and Contaminants in the Greater Everglades Ecosystem: Past, Present, and Future', Critical Reviews in Environmental Science and Technology. 41: 6, 121-148.

Osborne, Todd Z., Reddy, K.R., Ellis, L. R., Aumen, N. G., Surratt, D. D., Zimmerman, M. S. Sadle, J. (2013). Evidence of Recent Phosphorus Enrichment in Surface Soils of Taylor Slough and Northeast Everglades National Park, Society of Wetland science. 34: $37-45$.

Osborne, Todd Z., Bruland, L.G., Newman. S., Reddy, K.R., Grunwald, S. (2011). Spatial distributions and eco-partitioning of soil biogeochemical properties in the Everglades National park. Environment Monitoring Assessment. 183: 395-408 
Payne G, Weaver K, Bennett T (2003) Development of a numeric P criterion for the Everglades protection area. In: 2003 Everglades consolidated report. South Florida Water Management District, West Palm Beach, Florida

Perry. W. (2004). Elements of South Floridas's Comprehensive Everglades Restoration Plan. Ecotoxicology. 13: 185 - 193.

Polle-Schade, K. and Moller, G. (2016). Impact of Mitigation of Nutrient Pollution and Overland Water Flow Change on the Florida Everglades, USA, Sustainability. 940: 1-20.

Reddy, K. R., Newman, S., Grunwald, S., Osborne, T. Z., Corstanje, R., Bruland, G. L., and Rivero, R. G. (2005). Everglades soil mapping final report. West Palm Beach, FL: South Florida Water Management District.

Ross, M.S., Mitchell-Brucker, S, Sah, J.P., Stothoff, S., Ruiz, P.L., Reed, D.L., Jayachandran, K., Coultas, C.L. (2006). Interaction of hydrology and nutrient limitation in Ridge and Slough landscape of southern Florida. Hyrdobiologia. 569: 37-59.

Scheidt, D. J. and P. I. Kalla. (2007). Everglades ecosystem assessment: water management, water quality, eutrophication, mercury contamination, soils and habitat. Monitoring for adaptive management: a R-EMAP status report. EPA 904-R-07-001.

United States Environmental Protection Agency. Atlanta, Georgia

Surratt, D., and Aumen, N.G., (2014). Factor influencing Phosphous Levels Delivered to Everglades National Park. 54: 223-239

Sklar, F., McVoy, C., VanZee, R., Gawlik, D.E., Tarboton, K., Rudnick, D., Miao, S. and Armentano, T., (2002) The effects of altered hydrology on the ecology of the Everglades. The Everglades, Florida bay and coral reefs of the Florida Keys: an ecosystem sourcebook. CRC Press, Boca Raton, FL.

Smith, E.P. \& McCormick, P.V. (2001). Long-term relationship between Phosphorus inputs and wetland Phosphorus concentrations in a Northern Everglades Marsh. 68: 153-171.

Sklar FH, Chimney MJ, Newman S, McCormick P, Gawlik D, Miao SL, et al. (2005) The Ecological-societal underpinnings of Everglades restoration. Frontiers in Ecology and the Environment. 3:161-169

Thomas Davison, Jodie Hansing, Carmela Bedregal, and Pamela Wade (2017) Chapter 4: Nutrient Source Control Programs, in 2017 South Florida Environmental Report (SFER) Volume I 
Wang, Q., Y. Li, and Y. Ouyang. 2011. Phosphorus fractionation and distribution in sediments from wetlands and canals of a water conservation area in the Florida Everglades, Water Resource Research. 47:1-11

Zapata-Rios, X., R. G. Rivero, G. M. Naja, and P. Goovaerts (2012), Spatial and temporal Phosphorus distribution changes in a large wetland ecosystem, Water Resource. Research. 48: 95-112. 


\section{Appendix}

1. FCE LTER data repository link:

http://fcelter.fiu.edu/data/core/metadata/?datasetid=FCE121 